NBER WORKING PAPER SERIES

\title{
THE DERIVATION OF DISCOUNT RATES WITH AN AUGMENTED MEASURE OF INCOME.
}

Nicholas Z. Muller

Working Paper 22579

http://www.nber.org/papers/w22579

\author{
NATIONAL BUREAU OF ECONOMIC RESEARCH \\ 1050 Massachusetts Avenue \\ Cambridge, MA 02138 \\ August 2016
}

I would like to thank Peter Matthews for early input on the paper. I also acknowledge helpful comments from seminar participants at the University of Minnesota, the University of Michigan, and the University of East Anglia. The views expressed herein are those of the author and do not necessarily reflect the views of the National Bureau of Economic Research.

NBER working papers are circulated for discussion and comment purposes. They have not been peer-reviewed or been subject to the review by the NBER Board of Directors that accompanies official NBER publications.

(C) 2016 by Nicholas Z. Muller. All rights reserved. Short sections of text, not to exceed two paragraphs, may be quoted without explicit permission provided that full credit, including (C) notice, is given to the source. 
The Derivation of Discount Rates with an Augmented Measure of Income.

Nicholas Z. Muller

NBER Working Paper No. 22579

August 2016

JEL No. H23,H43,Q51,Q53,Q56

\begin{abstract}
Most developed economies invest in public goods such as national defense, education, infrastructure, and the environment. Expenditures on public projects entail a diversion of funds away from investments in private capital. Discount rates used to evaluate such projects should reflect the rate of return on the current mix of investment opportunities. The present paper derives discount rates using an augmented measure of national income inclusive of non-market goods. The discount rate reflects three key factors: the productivity of private capital, the opportunity cost of direct expenditure on public projects, and the returns to public investment that accrete outside of the market boundary. The difference between this social rate and the market rate depends on the latter two factors. In the first empirical calculation of discount rates in this setting, the paper reports that, in the U.S. economy, the difference between augmented and market discount rates amounts to 1.24 percent from 1999 to 2002 and under 1 percent from 2002 to 2011 .
\end{abstract}

Nicholas Z. Muller

Department of Economics

Warner Hall, 305D

Middlebury College

303 College Street

Middlebury, VT 05753

and NBER

nicholas.muller74@gmail.com 


\section{Introduction.}

Most developed economies invest in public goods such as national defense, education, infrastructure, and the environment. Holding total investment fixed, expenditures on public projects entail a diversion of funds away from market consumption or investments in private capital. Such projects are often evaluated using Net Present Value (NPV) analysis. The appropriate discount rate with which to evaluate public projects must reflect the rate of return on social investment opportunities (Baumol, 1968). This provides the relevant benchmark against which NPV conclusions are drawn. A government is likely to hold a mix of positions in private capital and a direct stake in public projects. Calculating returns on such a portfolio requires the rate of return on private capital and the yield on investments in public goods. Evaluation of the former depends on readily available market data. Critically, determining the latter may demand data that lies beyond the market boundary. Measuring only those returns to public good investments that accrue within the market may produce biased estimates of the yield on public projects. This bias would, in turn, manifest in the social discount rate. In light of this, the present paper suggests using an augmented measure of income to evaluate both market and non-market returns. This facilitates estimating an appropriate social discount rate and conducting meaningful NPV analysis for public projects.

Economists tend to base estimates of the discount rate used in NPV calculations on interest rates in financial markets, the rate of return on private capital, or the utilityneutral rate of savings (Gollier, 2011). Despite these rather crisp recommendations, estimating the social discount rate has long-occupied economists (Steiner 1959; Marglin, 1963a; 1963b; Baumol, 1968; Bradford, 1975; Mendelsohn, 1981; Weitzman, 1994). More recently, the economics of climate change has rekindled the debate surrounding the appropriate discount rate (Stern, 2007; Nordhaus 2007). While not proposing to settle ongoing discussions regarding the "right" social discount rate, the present paper offers a fresh perspective on this topic by deriving discount rates for public projects using an augmented measure of national income inclusive of non-market goods. This tack 
permits expenditure on public goods to both (1) reduce the rate of return on saving by diverting funds away from private capital (which earns a rate of return that is known and measurable within the NIPAs), and, critically, (2) to affect the level of public goods and services, which then, in turn, permutes augmented output. When calculated in such a framework, the discount rate reflects three key factors: the productivity of private capital, the opportunity cost of direct expenditure on public projects, and the returns to public investment that accrete outside of the market boundary. The social rate is compared to the more conventional return on private capital to show under what conditions these rates differ and how.

This paper employs an analytical framework based on the National Income and Product Accounts (NIPAs). The NIPAs are a widely-used and internationally accepted approach to tracking economic activity (USBEA, 2007). By construction, they do not encompass economic activity that occurs outside the market boundary. (Though the tools developed in this paper apply to a range of non-market entities, because of the specific empirical application that zeroes-in on environmental externality, the discussion here focuses on this area.) ${ }^{1}$ Using the empirical NIPAs and the Ramsey rule, private or market discount rates for the United States (U.S.) economy from 1999 to 2011 are estimated. Then an integrated assessment model is used to calculate pollution damage and augmented discount rates for the U.S. economy over the same time period.

The analytical modeling in this study builds on the approach to distilling discount rates from a NIPA framework developed by Weitzman (1994), who explored differences between market rates of discount and rates that reflect the diversion of some investment to pollution abatement expenditure. Intuitively, expenditures on maintaining environmental quality necessitated by binding policy constraints effectively ratchet back gains from saving (and, hence, the discount rate) because some of the returns from

\footnotetext{
${ }^{1}$ Broadly, the literature refers to environmental quality and natural resources as natural capital and it is straightforward to extend the concepts raised herein to investments in these other areas (see Heal, 2009; 2012; Maler, Aniyar, Jansson, 2008).
} 
investment in private capital are diverted to abatement. This result, reported by Weitzman (1994), is a clear elicitation of the need to employ an augmented measure of output in the presence of external economies; because a market-centered accounting framework does not allow environmental damage to directly affect income, abatement can only adversely affect the return to savings and lower the discount rate. This approach assumes that abatement expenditure (investment in public goods) is less productive than investment in private capital simply because the returns to investment manifest outside the scope of income in the NIPAs. More broadly, if the outcome measure does not include the services generated by a public good, then investments made by society in such a good will appear to be unproductive. In marked contrast, the present paper employs an income measure that includes non-market goods. This enables one to more comprehensively calculate the rate of return on investments in environmental quality, and hence, to more appropriately characterize the social discount rate.

The paper also empirically estimates damages from air pollution and greenhouse gas (GHG) emissions in the U.S. from 1999 to 2011. Air pollutants included in the empirical analysis are: fine particulate matter $\left(\mathrm{PM}_{2.5}\right)$, sulfur dioxide $\left(\mathrm{SO}_{2}\right)$, nitrogen oxides $\left(\mathrm{NO}_{\mathrm{x}}\right)$, volatile organic compounds (VOCs), and ammonia $\left(\mathrm{NH}_{3}\right)$. The air pollution damages are estimated using an integrated assessment model (IAM) that is calibrated to the U.S. economy over this 12 year period. The damages are computed by first estimating pollutant-and-source-specific marginal damages, and then multiplying these pollution "prices" times reported emission "quantities". Thus, Gross External Damages (GED) are computed in a manner that is directly analogous to how market indices such as GDP are calculated (Nordhaus, 2006; Muller, Mendelsohn, Nordhaus, 2011). The IAM used has been widely applied in peer-reviewed studies (Holland et al., 2015; Muller, 2011; 2014a; 2014b; Muller, Mendelsohn, Nordhaus, 2011; NAS NRC, 2011; Michalek et al., 2011). The particular parameter values and assumptions that are embodied in the IAM are quite standard and are discussed at length in section III. 
The inclusion of 2011, the most recent year for which comprehensive emissions estimates are provided (USEPA, 2014), comprises the first post-Great Recession observation of air pollution damage. The addition of this data year is an extension relative to prior related research (Muller, 2014b). This in an especially important update to prior work in the field because of the dramatic realignments and structural changes that manifest in the U.S. economy after the financial crisis of 2008 and the subsequent downturn.

The damage estimates are then subtracted from GDP to calculate a measure of adjusted output. Growth in this augmented measure of output is computed and compared to market growth. Using the Ramsey formula (1928) the paper estimates the difference in discount rates that rely on market relative to augmented output.

\section{a. Summary of Key Results.}

The national accounting approach is used to derive expressions for three discount rates: market, environmental, and augmented discount rates. The market rate is simply the rate of return on private capital. The "environmental" rate is derived by including an explicit characterization of abatement expenditure in the accounting identity (Weitzman, 1994). It is the rate of return on capital less the drag due to diversion of investment returns from output to abatement. If more output yields more abatement, the environmental rate is lower than the market rate.

The augmented discount rate is derived by including both abatement and environmental pollution damage into the national income identity. The augmented rate is the rate of return on capital minus the partial effect of income on damages and abatement. If we assume that additional output yields more abatement, then in an economy with damages that rise with income, the augmented discount rate is less than the market rate. All else equal, rising damages place a drag on augmented growth (Muller, 2014a; 2014b). This effect reinforces the drag from abatement. 
In contrast, in a growing economy with falling damage, the effect of damages works against the drag due to abatement. Since growth is enhanced by the attenuation of damage the augmented discount rate will exceed the market rate if additional output produces less additional abatement than damage reduction. In the case where more output generates a greater expenditure on abatement than reduction in damage, the augmented rate will fall short of the market rate.

The analytical model also reveals that for the idealized case of an economy subject to efficient pollution control, the augmented discount rate will equal the market rate. The drag on investment due to diversion of funds to abatement is exactly offset by the reduction in damage. Since these two factors cancel out, we are left with the marginal productivity of capital as the appropriate discount rate.

The empirical section of the paper reports that Gross External Damages (GED) from air pollution and GHGs amounted to $\$ 770$ billion in 1999 and that this fell to $\$ 423$ billion in 2011, in real terms. Expressed relative to GDP, GED fell from 8.4 percent of output in 1999 to 3.6 percent in 2011. Thus, damages fell both in absolute and relative terms. Connecting these empirical results back to the analytical results discussed above, the U.S. economy exhibited an inverse relationship between the magnitude of national income and pollution damage over the 12 year period covered by this analysis.

Employing reported GDP and the pollution damage estimates noted above, the difference between augmented and market growth rates ranged from 0.6 percent (1999 to 2002) to 0.3 percent (2002 to 2011), (Muller, 2014a; 2014b). Employing a simple characterization of the spread between augmented and market discount rates derived using the Ramsey formula, along with a value of two for the elasticity of the marginal utility of income, the difference amounts to 1.24 percent from 1999 to 2002 . The divergence then falls to under 1 percent for the remaining years under study. The social discount rate exceeds the market rate because damage was falling over this time period. 


\section{b. Related Literature.}

In addition to the early literature on the social discount rate (Steiner 1959; Marglin, 1963a; 1963b; Baumol, 1968; Bradford, 1975; Mendelsohn, 1981), this paper builds on a few areas of the more recent environmental economics literature. First, Weitzman (1994) explores how discount rates are affected by including an explicit representation of expenditures on pollution abatement in a national income accounting framework. Importantly, Weitzman (1994) holds the level of environmental disamenity fixed between two time periods. In the present paper, damages change endogenously based on output, abatement levels, and the responsiveness of environmental quality to abatement effort. This more flexible approach highlights that the difference between market and augmented discount rates may be positive or negative depending on if and how damages change. When damages are constant, as in Weitzman (1994), the difference in the discount rates reduces to the opportunity cost of diverting savings away from productive capital to abatement.

The paper also relates to the literature on endogenous discounting (see Epstein and Hynes, 1983; Das, 2003; Le Kama and Schubert, 2007). Within this literature, Six and Wirl (2015) explore endogenous discount rates with a focus on climate change. In particular the authors assume that discount rates fall as environmental quality decreases, and they derive steady state outcomes associated with this case. In contrast, the present paper does not ex ante conjecture a relationship between environmental pollution damage and discount rates. Rather, this paper permits damages to increase, decrease, or remain fixed. Further, the present analysis allows society to choose abatement investments which endogenously affect damages and, in turn, discount rates. Thus, the Six and Wirl (2015) study focuses on a subset of relevant cases whereas the current paper presents a more general analysis that permits damages to vary with both output and abatement. 
Heal (2009) explores measures of growth in the Ramsey formula over a disaggregated measure of consumption. The impetus for this disaggregation is the distinction between conventional consumption goods and a measure of natural or environmental capital. Heal (2009) notes the possibility that one type of consumption (market, for instance) may increase while another (environmental services) may fall. The correspondence of, or relevance to, the present paper is obvious. However, the main thrust of Heal's (2009) work lies in (i) distinguishing multiple types of consumption, and (ii) the nature of the elasticity of substitution between natural and man-made capital.

One implication of the analytical modeling conducted herein is a variable term structure. This relates to the literature focusing on declining discount rates (Weitzman, 2001; Cropper et al., 2014). The paper also is linked to the work of Gollier (2008) who explores the implications of uncertainty in future economic growth for the determination of discount rates.

Another connection to the literature manifests in the area of environmental accounting. Specifically, the calculation of air pollution and GHG damages builds on several papers (Muller and Mendelsohn, 2009, Levy et al., 2009). The inclusion of such damages into an augmented accounting system connects to earlier papers including: Bartelmus, 2009; Muller, Mendelsohn, Nordhaus, 2011; Muller, 2014a. Estimation of augmented growth rates links to Muller, 2014a; 2014b. There is also a literature exploring the idea of inclusive wealth which is basically defined to augment conventional notions of wealth with various measures of natural capital (Polasky et al., 2015). Aside from the obvious conceptual connection to the present paper, the findings from this literature seem to indicate that augmented measures of output decline relative to the market analogs. It is perhaps noteworthy that the present analysis reports measures of augmented output that grow more rapidly than market output.

The remaining sections of the paper include the following. Section I. which lays out the structure of the analytical model and derives various expressions for the discount rates, 
and section II. which introduces the empirical model and data sources. Section III. reports empirical results and IV. concludes.

\section{Analytical Models.}

This section proceeds in two parts. First, a national income accounting framework is used to derive market, environmental, and augmented discount rates. These rates are then compared and the differences are expressed in terms of the parsimonious structure of the income accounting identity. Next, the Ramsey (1928) formula for discount rates is used to derive an expression for the difference between augmented and market discount rates that is directly applicable to the empirical section of the paper based on available data.

\section{a. Discount Rates in the National Income Accounting Framework.}

This section uses a national income accounting framework to derive three discount rates: a market rate, Weitzman's "environmental rate", and an augmented rate based on an augmented measure of output inclusive of pollution damage. In the market accounts, without damages or an explicit treatment of pollution abatement, the (market) return to savings manifests only through conventional channels: the productivity of private capital, $(1+r)>1$. Next, in replicating Weitzman's (1994) environmental discount rate, some of the return from savings is diverted to abatement. So the augmentation in this case is partial; abatement is in effect a distinct category of investment. And third, an accounting framework that is inclusive of abatement and environmental damage is constructed and used to derive the augmented rate of return on savings. The key distinction between this third approach and the prior two (and the literature) is that the latter permits the allocation of savings to abatement to reduce environmental harm.

The derivation proceeds in the following steps ${ }^{2}$.

1) Implement a shock to investment (savings) in period (t), denoted $\varepsilon_{t}$.

${ }^{2}$ The mathematical appendix displays these steps more explicitly. 
2) In the market account, track savings through output $\left(Y_{t}\right)$.

3) In the partial augmentation which includes abatement, track savings, through output, to abatement.

4) In the fully augmented account, track savings, through output, to abatement and environmental damage.

5) Solve for the income balancing level of consumption in all three accounts.

6) Subtract consumption without savings from consumption with savings and divide through by $\varepsilon_{t}$ in all three accounts.

Like Weitzman (1994) and ultimately Solow (1956), output is expressed in terms of one commodity. Further, this homogeneous output $\left(Y_{t}\right)$ is expressed in terms of the standard accounting identity ${ }^{3}$ shown in (1).

$Y_{t}=C_{t}+I_{t}+G_{t}+X_{t}$

where:

$C_{t}=$ consumption of market goods.

$I_{t}=K_{t}-\lambda K_{t-1}$ : net investment in physical capital, where $\lambda$ is the depreciation of physical capital.

$G_{t}=$ government expenditure.

$X_{t}=$ net exports.

Next, the standard framework is augmented in two ways that are pertinent to the focus on environmental externality. Let $A_{t}$ represent investment in environmental quality, natural capital, or more specifically, expenditure on abatement of pollution. This is defined as a linear function of income: $A_{t}=\gamma Y_{t}$, where $(0 \leq \gamma \leq 1)$. This extension is shown in (2).

$Y_{t}-\gamma Y_{t}=C_{t}+I_{t}+G_{t}+X_{t}$

\footnotetext{
${ }^{3}$ In a Solow (1956)-type framework, output at time $(t)$, denoted $Y_{t}$, is expressed as a function of capital $\left(K_{t}\right)$ and labor $\left(\mathrm{L}_{\mathrm{t}}\right)$. The thrust of the present paper, augmented measures of output, does not require the use of a particular production function with distinct arguments for $\mathrm{K}_{\mathrm{t}}$ and $\mathrm{L}_{\mathrm{t}}$.
} 
Rather than a true augmentation of costs and benefits external to the market, (2) really just separates $\gamma Y_{t}$ from $C_{t}$ or $G_{t}$. That is, expenditures on abatement (and, generally, investments in natural capital) typically occur within the market boundary in the form of investment in either physical capital or clean inputs.

The second extension features the inclusion of environmental damage in the expression for income. Damage, or degradation of natural capital, is modeled as a linear function of income and abatement: $D_{t}=\alpha Y_{t}-\beta\left(\gamma Y_{t}\right)$. The $(\alpha)$ parameter represents the pollutionintensity of output, while the $(\beta)$ parameter reflects the sensitivity of environmental damage to investment in abatement. Mechanically, damage increases proportionally to output through $(\alpha)$, and decreases with income through investment in abatement $(\gamma)$. A large (small) value of $\beta$ suggests reducing damage requires relatively less (more) investment in abatement. The partial effect of output on environmental damage, $\frac{\partial D_{t}}{\partial Y_{t}}=\alpha-\beta \gamma$, depends on the difference between pollution intensity $(\alpha)$ and the product of the propensity to spend on abatement $(\gamma)$ and the effect of such expenditure on environmental quality $(\beta)$. These two effects from income growth balance when $\left(\frac{\partial D_{t}}{\partial Y_{t}}\right)=0$, which occurs if: $\gamma=\frac{\alpha}{\beta}$.

With $\left(D_{t}\right)$ characterizing environmental damage ${ }^{4}$ in time $(\mathfrak{t})$, environmentally-adjusted output is shown in (3).

$Y_{t}(1-\gamma-\alpha+\beta \gamma)=C_{t}+I_{t}+G_{t}+X_{t}$

\section{a. Savings, and changes to income, abatement, and damage.}

Expressions (4a) through (4c) show how savings propagate through the three different characterizations of income in expressions (1), (2), and (3).

\footnotetext{
${ }^{4}$ It is important to emphasize that the augmentation of the market accounts manifests as a deduction for damage due to environmental pollution. While there are many natural capital-oriented adjustments that could be made to national income such as the value of natural resources in situ, the paper is motivated by prior empirical evidence specifically reporting monetary damages from pollution so that is the focus here.
} 
Output in period $\mathrm{t}$, with an incremental increase in investment, denoted $\left(\varepsilon_{t}\right)$ is shown in (4a). Savings in productive capital yields $(1+r) \varepsilon_{t}$ which is added to output.

$Y_{t}+(1+r) \varepsilon_{t}=C_{t}+I_{t}+\varepsilon_{t}+G_{t}+X_{t}$

In (4b), the shock to income $(1+r) \varepsilon_{t}$ boosts output and abatement expenditure. Collecting terms results in:

$\left(Y_{t}+(1+r) \varepsilon_{t}\right)(1-\gamma)=C_{t}+I_{t}+\varepsilon_{t}+G_{t}+X_{t}$

Expression (4c) uses the augmented accounting identity in (3) to demonstrate how investment affects environmental damage in addition to abatement. Collecting terms on the left-hand side yields:

$\left(Y_{t}+(1+r) \varepsilon_{t}\right)(1-\gamma-\alpha+\beta \gamma)=C_{t+1}+I_{t+1}+\varepsilon_{t}+G_{t}+X_{t}$

\section{b. Derivation of discount rates.}

The approach used to derive discount rates in the market accounts solves for consumption with savings, using (4a), and without savings, using (1). Subtracting (1) from (4a) yields the change in consumption $(\Delta \mathrm{C})$ due to savings: $\Delta C=(1+r) \varepsilon_{t}-\varepsilon_{t}$. Then dividing through by $\left(\varepsilon_{t}\right)$ produces the familiar market rate of return on savings: the marginal productivity of capital investment:

$i^{m}=(1+r)-1=r$

Repeating this procedure with the accounts that recognize abatement yields:

$i^{e}=(1+r)-(1+r) \gamma-1=r-(1+r)\left(\frac{\partial A_{t}}{\partial Y_{t}}\right)$.

The increase in output, $\left(Y_{t}+(1+r) \varepsilon_{t}\right)$, triggers additional abatement. Differencing (2) from (4b) just with respect to abatement yields: $\gamma\left(Y_{t}+(1+r) \varepsilon_{t}-Y_{t}\right)=\gamma(1+r) \varepsilon_{t}$. Provided the reasonable assumption that $\gamma=\left(\frac{\partial A_{t}}{\partial Y_{t}}\right) \geq 0:(5 b) \leq(5 a)$. In $(5 b)$, the $-(1+$ r) $\left(\frac{\partial A_{t}}{\partial Y_{t}}\right)$ term reflects the opportunity cost of investment in abatement. These are the 
foregone returns from capital investment. This cost lowers the effective discount rate relative to the marginal product of capital. This is akin to the "drag" term identified by Weitzman (1994).

Thus far, channeling savings to pollution control is not productive because damage lies beyond the scope of income in (1) and (2). The augmented measure of income (3) accommodates pollution damage, and therefore, allows for abatement to yield returns through changes in damage. Solving for $\Delta \mathrm{C}$ in the augmented accounts framework of (3) and $(4 c)$, and then dividing through by the savings shock $\left(\varepsilon_{t}\right)$ produces $(5 c)$, the augmented discount rate.

$i^{a}=(1+r)(1-\alpha+\beta \gamma-\gamma)-1=r-(r+1)\left(\frac{\partial D_{t}}{\partial Y_{t}}+\frac{\partial A}{\partial Y_{t}}\right)$

Intuitively, the rate of return to savings in the augmented accounts depends on the partial effect of income on both abatement and environmental damage. As in (5b), the shock to output increases abatement by $\gamma(1+r) \varepsilon_{t}$. However, in the augmented accounting framework, the change in output from savings also changes damage: $\alpha\left(Y_{t}^{c}+(1+r) \varepsilon_{t}-Y_{t}^{c}\right)+\beta \gamma\left(Y_{t}^{c}-Y_{t}^{c}-(1+r) \varepsilon_{t}\right)=(1+r) \varepsilon_{t}(\alpha-\beta \gamma)$. This is simply the boost to output from savings times the partial effect of output on damages. The analysis next compares these rates.

\section{c. Comparing the discount rates.}

In this section, the focus is on the comparison between the market rate and the augmented rate. Other comparisons are found in the appendix. Subtracting (5a) from (5c), yields:

$$
i^{a}-i^{m}=-(r+1)\left(\left(\frac{\partial D_{t}}{\partial Y_{t}}\right)+\left(\frac{\partial A_{t}}{\partial Y_{t}}\right)\right) .
$$

The difference is comprised of both the partial effect of output on damage and abatement. Mechanically this manifests because the market accounts (and, therefore, the market discount rate) incorporates neither abatement nor damage. Whether abatement 
increases, decreases, or remains fixed with respect to income depends on social preferences. Whether and how damages change with income depends on the intensity of abatement expenditure $(\gamma)$, the responsiveness of the environment to abatement $(\beta)$, and the pollution intensity of output $(\alpha)$. Although there are many combinations of $\left(\frac{\partial A_{t}}{\partial Y_{t}}\right)$ and $\left(\frac{\partial D_{t}}{\partial Y_{t}}\right)$, this discussion assumes that $\left(\frac{\partial A_{t}}{\partial Y_{t}}\right) \geq 0$. Then, in an economy with damages that increase with income, (6) is unambiguously negative. In this case both increasing abatement and rising damages attenuate the gains from savings. Thus, the market rate exceeds the augmented rate ${ }^{5}$.

In a setting where damages fall with output the sign of (6) depends on the relative magnitudes of $\left(\frac{\partial D_{t}}{\partial Y_{t}}\right)$ and $\left(\frac{\partial A_{t}}{\partial Y_{t}}\right)$. The diversion of savings to abatement produces a drag on the returns to investment. Falling damages counteract this effect because damage itself is a drag on output. Thus, reductions in this non-market cost will, ceteris peribus, enhance output. The comparison between the augmented discount rate and the market rate hinges on which of these two effects dominates.

\section{d. Comparison of discount rates with efficient pollution control.}

If an idealized economy were subject to efficient pollution control, it is well-known that marginal abatement cost equates to marginal damage. In the present modeling context, the terms $\left(\frac{\partial D_{t}}{\partial Y_{t}}\right)$ and $\left(\frac{\partial A_{t}}{\partial Y_{t}}\right)$ reflect marginal pollution damage and marginal abatement cost of additional output, respectively. Efficiency requires that the opportunity cost in terms of foregone consumption due to investment in abatement, $\left(\frac{\partial A_{t}}{\partial Y_{t}}\right)$, will just balance the benefit of pollution reduction (the avoided environmental damage from one more unit of production) which is given by: $-\left(\frac{\partial D_{t}}{\partial Y_{t}}\right)$. In this efficient state, with $\left(\frac{\partial D_{t}}{\partial Y_{t}}\right)<0$, then $-\left(\frac{\partial D_{t}}{\partial Y_{t}}\right)=\left(\frac{\partial A_{t}}{\partial Y_{t}}\right)$, and then the social discount rate will equal the market rate because

${ }^{5}$ Further, if $\left(\left(\frac{\partial D_{t}}{\partial Y_{t}}\right)+\left(\frac{\partial A_{t}}{\partial Y_{t}}\right)\right)>\frac{r}{1+r}$, then the augmented rate will be negative. 
the $\left(\left(\frac{\partial D_{t}}{\partial Y_{t}}\right)+\left(\frac{\partial A_{t}}{\partial Y_{t}}\right)\right)$ term in (6) equals zero. At the margin, additional investment in abatement produces a cost in terms of foregone consumption that is just balanced by damage reduction. Thus, if pollution is efficiently regulated, the market and social discount rates converge ${ }^{6}$.

If $-\left(\frac{\partial D_{t}}{\partial Y_{t}}\right)=\left(\frac{\partial A_{t}}{\partial Y_{t}}\right)$ holds, then one can solve for the corresponding abatement intensity $(\gamma)$ which is given by: $\gamma=\alpha /(\beta-1)$. This expression is instructive in that it suggests three dimensions of intuitive behavior related to abatement choice in the case of optimal regulation of pollution. First, abatement is increasing in damage intensity of output $(\alpha)$. Second, $\gamma$ is only positive if $\beta>1$. And, $\beta>1$ implies that for each unit of money spent on abatement, damages fall by more than one unit of money. This also seems plausible as a rational society probably would not invest in abatement if, for each dollar spent, it is getting less than that back in environmental quality improvements. Third, as $\beta$ increases, $\gamma$ falls: $\partial \gamma / \partial \beta=-\alpha /(\beta-1)^{2}$.That is, as the environment becomes more (or less) responsive to abatement, the level of abatement that satisfies the $-\left(\frac{\partial D_{t}}{\partial Y_{t}}\right)=\left(\frac{\partial A_{t}}{\partial Y_{t}}\right)$ condition falls (or rises).

Three results from the analytical model bear summarization. (1) While the literature shows that investments in pollution control come at some opportunity cost, the augmented measure of income recognizes that rerouting savings to abatement yields benefits through reduced external costs. (2) The augmented discount rate may exceed or fall short of the market rate. With non-negative investment in abatement, the difference in rates depends on both the sign and the magnitude of the partial effect of output on damage. (3) In an efficient pollution control regime, $i^{a}=i^{m}$. This latter finding confirms that the present formulation is in accord with the well-known result that, if an economy

\footnotetext{
${ }^{6}$ This assumes that pollution externality is the only distortion in the economy.
} 
moves along its optimal path, the social discount rate will equal the marginal productivity of capital (Gollier, 2011).

\section{e. Discount Rates in the Context of the Ramsey Formula.}

This section relies on the Ramsey (1928) formula to derive a discount rate based on augmented income growth and to compare that with the rate based on market growth. A secondary purpose is to serve essentially as a robustness check for section II. Because of the relative parsimony of Ramsey (1928), this section provides a nice segue to the empirical analysis which uses the formulation in (10) below to estimate the difference between the market and augmented discount rates.

The familiar Ramsey (1928) formulation is shown in (7).

$r^{R}=\rho+\eta g$

The parameters in (7) assume their conventional meanings with $\rho=$ the pure rate of time preference; $\eta$ = the elasticity of the marginal utility of income; $g=$ annual, per capita income growth. In the following $(g)$ is replaced with a slightly more explicit representation of income growth to facilitate a comparison between market and augmented income ${ }^{7}$. Thus, (8), relies on market income, where $\left(Y_{t}\right)$ denotes national income in time period $(t)$.

$r_{m}^{R}=\rho+\eta\left(\frac{Y_{t+1}-Y_{t}}{Y_{t}}\right)$

Expression (9) employs the augmented measure of national output: $\left(Y_{t}-\alpha_{t} Y_{t}\right)$, where $\alpha_{t}$ represents pollution damage intensity of output. Therefore, $\alpha_{t} Y_{t}=D_{t}$.

$r_{s}^{R}=\rho+\eta\left(\frac{\left(Y_{t+1}-\alpha_{t+1} Y_{t+1}\right)-\left(Y_{t}-\alpha_{t} Y_{t}\right)}{Y_{t}-\alpha_{t} Y_{t}}\right)$

\footnotetext{
7 The decomposition of growth into market output and pollution damage, or degradation of natural capital, is akin to the characterization of growth over a vector of goods proposed in Heal (2009). In that framework, Heal specifies consumption of market goods and services and natural capital. Heal (2009) then permits growth rates to vary over these categories.
} 
Then, taking the difference by subtracting (8) from (9) yields:

$\Delta=r_{s}^{R}-r_{m}^{R}=\eta \frac{Y_{t+1}}{Y_{t}}\left(\frac{\left(\alpha_{t}-\alpha_{t+1}\right)}{1-\alpha_{t}}\right)$

This expression reveals a few important relations. First, the pure rate of time preference does not factor into the difference. Hence, views regarding the appropriate choice of the pure rate of time preference based on positive versus normative positions held by the analyst are irrelevant to the divergence in rates due to using market or augmented income (Arrow et al., 1995). Second, the difference is increasing in $\eta$ and in the gross rate of change in market income. Third, the difference depends on the change in pollution intensity between the time periods over which growth is reported, and how the money value of environmental damage compares to aggregate output in the base period.

The augmented discount rate will exceed the market rate provided the following two conditions hold. First, the money value of environmental disamenity is less than output in the base period: $\alpha_{t}<1$. This seems likely to hold in many modern economies ${ }^{8}$. Second, pollution intensity is falling: $\alpha_{t}>\alpha_{t+1}$. If pollution intensity is rising (and $\left.\alpha_{t}<1\right)$ the augmented discount rate will fall short of the market rate.

Conversely, in severely degraded environments such that $\left(1-\alpha_{t}\right)<0$, if pollution intensity is falling, the augmented rate will fall below the market rate. If $\left(1-\alpha_{t}\right)<0$, and pollution intensity is rising, the discount rate tabulated using augmented income growth will exceed that computed using market income.

The next step is to synthesize the results from the Ramsey framework with the national accounting approach. Recall from (6) that the difference between augmented and market discount rates is inversely related to $\left(\frac{\partial D_{t}}{\partial Y_{t}}\right)$. Expression (10), indicates that the

\footnotetext{
8 For example, the empirical section of the present analysis reports that, even as far back as 1999, pollution and GHG damages amounted to under 10 percent of GDP in the U.S. Further, in Muller, Mendelsohn, and Nordhaus (2011) a small fraction of industries were reported to have GED in excess of value-added.
} 
spread between the augmented and market rates depends on the relative magnitudes of $\alpha_{t}$ and $\alpha_{t+1}$. Notice, however, that these parameters represent $\left(\frac{\partial D_{t}}{\partial Y_{t}}\right)$ and $\left(\frac{\partial D_{t+1}}{\partial Y_{t+1}}\right)$ in the Ramsey model ${ }^{9}$. Increasing damage intensity from period $\left(\frac{\partial D_{t}}{\partial Y_{t}}\right)$ to $\left(\frac{\partial D_{t+1}}{\partial Y_{t+1}}\right)$, produces a lower augmented rate than the market rates (provided $\left.\left(\frac{\partial D_{t}}{\partial Y_{t}}\right)<1\right)^{10}$. Falling damage intensity suggests a higher augmented rate.

It is expected that both modeling frameworks suggest that the partial effect of income on environmental pollution damage is central to the difference in the discount rates because the augmentation to the market accounts is focused on damage. However, the consistency in how damages affect the discount rates is reassuring. Rising damage intensity over time (in the Ramsey model) and a positive partial effect of output on damage (in the national accounting model) both imply augmented discount rates that are lower than market rates. Conversely, damage intensity that falls over time and a negative partial effect of output on damage suggest augmented rates that exceed market rates. Hence, the differences between (6) and (10) come from the structure or specification of the modeling framework.

The next section of the paper discusses the data and empirical modeling. Further, section III. shows how the empirical model is calibrated to the U.S. economy.

\section{Empirical Model and Calibration to U.S Economy.}

This section calibrates the parameters in the Ramsey formula to the U.S. economy over the period 1999 to 2011. Expression (10) is used to approximate the difference between augmented and market rates. Many different data sources are required to execute this calibration. Required are estimates of market output (GDP), the elasticity of the marginal utility of income, and pollution damages.

\footnotetext{
${ }^{9}$ The Ramsey model subsumes investment in, or expenditure on, abatement in $Y_{\mathrm{t}}$.

${ }^{10}$ Note that this expression substitutes the partial effect of income on damage for alpha.
} 
The empirical analysis relies on economy-wide Gross Domestic Product (GDP) reported by the U.S. Bureau of Economic Analysis (USBEA, 2014) and accompanying GDP deflators. For environmental damage, empirical estimates of damages from local air pollutants (GED) are produced using the AP2 model11 (Holland et al., 2015; Muller, 2011; 2014a; 2014b, Jaramillo and Muller, 2016), which is an updated version of the APEEP model (Muller and Mendelsohn, 2007; 2009; Muller, Mendelsohn, Nordhaus, 2011; NAS NRC, 2010; Michalek et al., 2011). The AP2 model is an integrated assessment model (IAM) for local air pollution that covers the following five pollutants: ammonia $\left(\mathrm{NH}_{3}\right)$, sulfur dioxide $\left(\mathrm{SO}_{2}\right)$, nitrogen oxide $\left(\mathrm{NO}_{\mathrm{x}}\right)$, fine particulate matter ( $\mathrm{PM}_{2.5}$ ), and volatile organic compounds (VOC). The model tracks emissions of these pollution species that are reported by the U.S. Environmental Protection Agency (USEPA) for the following years: 1999, 2002, 2005, 2008, 2011 (see USEPA, 2002; 2005; $2008 ; 2011 ; 2014$ ). Emissions are reported by source type (mobile versus stationary, for instance) and by the county of release.

An air quality model in AP2 converts emissions into annual average pollution concentration estimates for each county in the contiguous U.S. Specifically, the model employs a series of source-receptor matrices that characterize the effect of an incremental emission (one ton, say) from source (j) on air quality in receptor county (i). There are distinct matrices for each emitted pollutant and for four different source classifications: ground-level emissions and point source emissions from 3 different effective height classes. Ground-level emissions encompass discharges from vehicles, households, and small commercial facilities without an individually monitored smokestack. Point sources are divided into those with an effective height of emissions of less than 250 meters, 250 - 500 meters, and those over 500 meters. The last category consists of 656 of the largest industrial air pollution sources in the lower-48 states. Most of these are fossil fuel fired power plants. The predictions of the air quality model in

\footnotetext{
${ }^{11}$ The current analysis consists of a mix of empirical results reported in prior papers (Muller, 2014b) and new results for the most current model year (2011).
} 
AP2 have been tested against ambient pollution monitors maintained by the USEPA. (See Jaramillo and Muller, 2016 for the most recent diagnostic tests of AP2.)

With predicted concentrations, the model computes population exposures in each county. This is accomplished using population estimates provided by the U.S. Census Bureau (Census, 2015). Exposures to other sensitive "receptors" are also modeled. Specifically, yields of crop and timber species that have been shown to be adversely affected by local air pollution (USEPA, 2011) are gathered from the U.S. Department of Agriculture (USDA, 2015) at the county level. Population and USDA data are gathered for each model year.

Converting exposure into physical effects (cases of illness, tons of crop yield lost) relies on dose-response or concentration-response functions. Paramount among these are the functional relationships between adult mortality rates and exposure to $\mathrm{PM}_{2.5}$ and tropospheric ozone $\left(\mathrm{O}_{3}\right)$. The adult mortality- $\mathrm{PM}_{2.5}$ link is modeled using the function reported in Pope et al., (2002), and for $\mathrm{O}_{3}$ exposure the results from Bell et al., (2004) are used. These are fairly standard assumptions in the air pollution damage measurement literature. Baseline incidence data is provided by the Centers for Disease Control and Prevention (CDC, 2015), and, as above, these data are provided for each modeled year. Thus, as population size, spatial distribution, and vitals change, the model picks this evolution up.

Each damage endpoint (health effects, crop and timber loss, etc.) are then converted to monetary equivalents. For market effects (like crop and timber yields) current market prices are used. For impacts on services not traded in markets, mortality risk for example, values reported in the non-market valuation literature are employed. So, to value changes in mortality risk due to differential pollution exposure, the AP2 model employs the Value of a Statistical Life (VSL) approach (Viscusi, Aldy, 2003). This is a standard tack, and the particular VSL used herein is also typical: about \$6 million (in year-2000 USD). 


\section{a. Computing Marginal Damage and Integration into the National Accounts.}

Because the damages from air pollution are ultimately integrated into an augmented accounting system, the approach to estimating aggregate damages reflects the approach to tabulating the gross value of production embodied in GDP. That is, total damage is the product of emissions (quantity) times marginal damage (loosely, the price of emissions). This approach is recommended in the environmental accounting literature (Nordhaus, 2006).

Marginal damages are computed using the algorithm first developed and applied by Muller and Mendelsohn (2007; 2009). This entails the following steps. First, for a given time period (say, 2011) baseline emissions reported by the USEPA are processed through the AP2 model to compute concentrations, exposures, physical effects, and monetary damages. The baseline gross damage number is stored. Next, one ton of one pollutant, $\mathrm{PM}_{2.5}$ for example, is added to baseline emissions from source (j). The AP2 model is re-run and new concentrations, exposures, physical effects, and money damages are tabulated. The difference between the new damage figure and the baseline gross damage constitutes the marginal (\$/ton) damage for source (j) emissions of $\mathrm{PM}_{2.5}$. This is captured in (11).

$M D_{j, t, s}=\sum_{r=1}^{R} D_{r, t, s}^{+1}-D_{r, t, s}^{b}$

where: $D_{r, t, s}^{+1}=$ damage in county $(\mathrm{r})$, time $(\mathrm{t})$, exposure to pollutant (s) after adding one ton of pollutant (s) to baseline emissions.

$D_{r, t, s}^{b}=$ damage in county $(\mathrm{r})$, time $(\mathrm{t})$, exposure to pollutant (s), conditional on baseline emissions.

$\mathrm{R}=$ total number of receptor counties.

Note that the marginal damage is a spatial sum over receptor counties subsequent to the additional ton emitted by source (j). The AP2 model then cycles through the remaining $(N=9,983)$ sources and five pollutants to produce a total of 50,000 source- 
and-pollutant-specific marginal damage estimates for each of the five years covered in the analysis.

Total damages, or GED, are computed as the product of emissions and marginal damages, matched by source and pollutant. This is depicted in (12) which shows that economy-wide GED is the sum across pollutants (S), sources (J), and sectors (I).

$G E D_{t}=\sum_{i=1}^{I} \sum_{j=1}^{J} \sum_{s=1}^{S} E_{j, i, t, s} \times M D_{j, i, t, s}$

In time period $(t)$ the empirical estimate of the coefficient of pollution intensity in the Ramsey model is: $\alpha_{t}=\frac{G E D_{t}}{G D P_{t}}$. The empirical analog to expression (3) is produced by subtracting the GED from GDP as shown in (13), where EVA denotes environmentallyadjusted value added (Muller, 2014a; 2014b).

$E V A_{t}=G D P_{t}-G E D_{t}$

\section{b. Damages from greenhouse gas emissions.}

The damages from greenhouse gases are estimated using an analogous price times quantity approach. This involves the application of a Social Cost of Carbon (SCC) estimate which is essentially the present value of damage caused by emitting one ton of carbon dioxide $\left(\mathrm{CO}_{2}\right)$. The AP2 model is not a device that can compute the SCC. As such, the analysis turns to recent meta-analyses for SCC estimates. In particular, the SCC value reported by the U.S. Federal Government's Inter-Agency Working Group on the Social Cost of Carbon is used. The SCC is about $\$ 35 /$ ton $\mathrm{CO}_{2}$. This SCC is multiplied times emission estimates for the entire U.S. economy, because, unlike emissions of local air pollutants, the damage from emissions of $\mathrm{CO}_{2}$ is independent of the location of emission. Thus, one marginal damage is applied to all emissions.

\section{c. Deflation and Real GED.}

Market macroeconomic aggregates are deflated using the GDP deflators reported by the USBEA. GED is deflated using the techniques reported in Muller (2013). This entails the 
estimation of pollution specific fixed base (2005) price deflators. The pollution price deflators assume the Fisher index form (see Muller, 2013). Real GED is:

$G E D_{t}=\sum_{i=1}^{I} \sum_{j=1}^{J} \sum_{s=1}^{S} E_{j, i, t, s} \times\left(M D_{j, i, t, s}\left(P_{t, s}^{f}\right)^{-1}\right)$

where: $\left(P_{t, s}^{f}\right)=$ Fisher pollution price index for pollution species $(\mathrm{s})$ at time $(\mathrm{t})$.

\section{Results.}

The results section proceeds as follows. Part a. focuses on the macroeconomic aggregates relevant to the study. These include GDP, GED, and the EVA measures. Section $b$. focuses on the calculation of discount rates using the Ramsey formulation generated in section II. Next, c. explores the implications of discount rates for discount factors applied to future costs and benefits. Finally, part d. examines the GED when calculated without GHGs. This isolates the relative effects of local air pollutants and GHGs on the discount rates reported herein.

\section{a. Macroeconomic aggregate indices.}

Table I summarizes some of the central empirical data that are subsequently used in the model to estimate discount rates for the time periods under consideration. Column (1) reports real GDP from 1999 to 2011. These results show that real GDP increased from 1999 to 2011. GDP is reported in three-year increments because this comports with the years for which emission data are available and hence damage estimates are provided. Column (2) shows the GED estimates (inclusive of both air pollution and greenhouse gases). In 1999, GED amounted to $\$ 768$ billion. The GED fell throughout the five years under study. In 2011, GED was \$423 billion which is just over one-half of GED in 1999. Column (3) presents the augmented measure of output which is defined as GDP less GED. The augmented output measure increased from \$8.4 trillion in 1999 to $\$ 11.4$ 
trillion in 2011. GDP, GED, and the augmented measure of output are shown in appendix figure A1.

Column (4) reports the pollution intensity of output. Table I indicates that pollution damage intensity fell from 1999 to 2011. In 1999, GED comprised over 8 percent of market output. This metric declined to 6.7 percent in 2002, 6 percent in 2005, and then just under 5 percent in 2008. Following the Great Recession, in 2011 the combined monetary value of air pollution and greenhouse gas damage amounted to 3.6 percent of total output. Figure A3 in the appendix shows the linear decline in pollution intensity in the U.S. economy.

Table II reports the annualized rates of growth in GDP, GED, and the augmented measure of output, EVA. The top panel of table II reports growth in absolute terms whereas the bottom panel displays per-capita growth rates. Beginning with the top panel of table II, annualized real GDP growth ranged between 1.2 and 2.8 percent. Note that the annualized growth rate was lowest between 2005 and 2008 as the U.S. economy approached the Great Recession. In contrast, annualized GED growth was consistently negative. From 1999 to 2002 GED fell by 4.9 percent. From 2002 to 2005 GED growth became less negative (-1.5 percent), and then from 2005 to 2008, GED fell by over 5 percent (Muller, 2014b). Between 2008 and 2011, GED fell by 7.5 percent on an annualized basis. Because GED growth was less than GDP growth, EVA expansion exceeded that of GDP. Specifically, column (3) of table II shows that growth in the environmentally-augmented indicator outpaced market output ${ }^{12}$ by between $0.6 \%$ and $0.3 \%$.

The bottom panel of table II reports per capita growth rates. In terms of GDP, normalizing by population ratchets back the rates of growth. GDP growth ranged from $0.2 \%$ to $1.9 \%$ over the time period under examination. In contrast, per-capita GED

\footnotetext{
${ }^{12}$ Note that for the 1999 to 2008 time periods, this result was shown in Muller $2014 \mathrm{~b}$. New to this analysis is the finding that the spread between market and augmented growth maintained at $0.3 \%$ from 2008 to 2011.
} 
growth fell by more than absolute GED growth. The per-capita EVA measure, like GDP grew more slowly than absolute EVA. The difference, however, that expressing the macroeconomic aggregate indices in per-capita terms exerts on the spread between market and EVA growth rates is quite modest.

\section{b. Discount Rates.}

Table III reports the discount rate analysis using the Ramsey formula. Note that $\left(r_{s}^{R}\right)$ denotes the augmented discount rate derived using augmented growth, whereas $\left(r_{m}^{R}\right)$ reflects the rate derived using market growth. For all values in table III, the pure rate of time preference is set to 0.02 . The first three columns (on the left-hand panel of the table) assume that the elasticity of marginal utility with respect to income is 2 . The difference between the market discount rate and the augmented or augmented rate is shown in the third column.

Employing growth estimates from 1999 to 2002, the difference between the augmented discount rate and the market rate is 1.24 percentage points. The difference falls to 0.58 percentage points for 2002 to 2005. This convergence occurs because the difference in growth (augmented less market) fell from 0.6 percent over 1999 to 2002 to 0.3 percent from 2002 to 2005 as reported in table II. The augmented and market discount rates differ by 0.77 percentage points from 2005 to 2008. And this divergence increases to nearly 0.9 percent from 2008 to 2011 . Since the other parameters in the Ramsey formula $(\eta, \delta)$ are held fixed, the difference in discount rates is driven entirely by the difference in growth rates.

In the Ramsey formulation, the spread between discount rates depends on the elasticity of the marginal utility of income. As such, the right-hand panel of table III explores the sensitivity of the gap between discount rates to two different values of $(\eta)$. With $(\eta=1)$, the gulf between the augmented and market discount rates shrinks to range from 0.62 percent (1999-2002) to 0.29 percent (2002 to 2005). The rank ordering of differences with respect to time remains the same. Predictably, by setting $(\eta=4)$ the dissimilarity 
between the two rates grows. From 1999 to 2002, the differences increases relative to the base case with $(\eta=2)$ to 2.48 percentage points. For each of the remaining time periods, the gap between the rates exceeds 1 percent. Using growth estimates from 2008 to 2011, the spread between the rates is over 1.75 percentage points.

\section{c. Implications for Discount Factors.}

Figure I shows the results from a set of hypothetical calculations intended to characterize how the difference between the augmented discount rate and the market discount rate affect present value calculations. Specifically, these calculations report the present value of $\$ 100$ million (in either costs or benefits) at time $(t)$, where $(t)$ ranges from zero to 100 years in the future. The discount rate value used to generate the figures correspond to eta $=2$, and the years 1999 to 2002. Figure I shows that the discount factors begin to diverge significantly about twenty years in the future $(t=20)$. The dotted line plots the ratio of the present value computed using the augmented rate to the present value computed using the market rate. This ratio falls steadily from unity at $t=0$ to 0.5 at about $t=50$. At $t=100$, the ratio is about 0.30 . Thus, the present value of $\$ 100$ million occurring 100 years in the future computed using the augmented discount rate is just $30 \%$ of that calculated using the market rate. While the calculations in this example rely on a hypothetical $\$ 100$ million future value, they are illustrative in showing the drastic difference in present value stemming from the use of the two different discount rates.

Figure II conducts a similar exercise to figure I. However, the thrust of figure II is the exploration of different values of eta. The solid black line replicates the dotted line in figure I. That is, it uses results for the case where eta $=2$. The dashed line in figure II employs eta $=4$. In this case the present value of $\$ 100$ million occurring 100 years in the future computed using the augmented discount rate is just $10 \%$ of that calculated using the market rate. Further, the dashed line presents the results for eta $=1$. Using this parameter value, the present value computed using the augmented discount rate is just 
under $60 \%$ of that calculated using the market rate. One conclusion that is readily apparent given the results in figures 1 and 2 is that present value calculations over long time horizons (like what one might encounter in the context of GHGs) are very sensitive to the choice of whether to employ a market or an augmented discount rate.

\section{d. The Contribution of Local Air Pollution and Greenhouse Gases.}

Table IV compares the macroeconomic aggregate indices, the GED and EVA, for the case without GHGs to the default approach reported in table I which includes both types of pollution. Intuitively, excluding GHGs from the analysis lowers GED and raises EVA in all time periods. Beginning in 1999, GED excluding GHGs amounts to 77\% of GED inclusive of both GHGs and local air pollutants. The share falls to $72 \%$ in 2002, $70 \%$ in 2005 , and $66 \%$ in 2008. In 2011, damages from just local air pollution amounted to about $63 \%$ of damages from both GHGs and local pollution. The share of the GED from local pollutants fell from 1999 to 2011 . However, local pollution still contributed nearly two-thirds of GED in 2011. Conversely, GED from GHGs began in 1999 at \$179 billion. GHG damage increased to $\$ 190$ billion in 2005 before falling to $\$ 155$ billion in 2011. Damage from GHGs dropped by 16 percent from 2008 to 2011.

Table IV indicates that EVA with only local air pollution damage counted in GED was 2\% higher than EVA with both local pollution and GHGs counted in GED in 1999 through 2008. In 2011, EVA inclusive of only local air pollution was just 1.4\% higher than EVA with both GHGs and local pollutants in GED. Between 1999 and 2011, pollution intensity fell from being about 2 percentage points lower without GHGs to 1.3 percentage points lower.

Table V displays the effect of excluding GHGs on the spreads between the augmented and market discount rates from 1999 to 2011 . For the case in which eta is set to 2, the differences are on the order of 0.1 to 0.3 percentage points. However, this difference is sensitive to eta. For example, with eta set to 4 , the difference in discounts rate for 19992002 is over 0.2. Both tables 4 and 5 reveal that (i) most of the GED is due to local air 
pollutants, and (ii) the impacts on growth and discount rates are mostly due to local air pollution damage.

\section{Conclusions.}

Many societies around the world invest in public goods which necessitate a diversion of funds away from market consumption or investments in private capital. Evaluation of such projects often relies on NPV analysis. In principle, the appropriate discount rate in an NPV calculation should reflect the rate of return on the current mix of investment opportunities. Estimation of such a rate depends on market data (to compute the opportunity cost of capital) and it may also depend on data that lies beyond the market boundary if public investments affect external costs or benefits. The present paper derives discount rates for public projects using an augmented measure of national income inclusive of non-market goods. The estimated discount rates reflect three key components: the productivity of private capital, the opportunity cost of direct expenditure on public projects, and the returns to public investment that accrete outside of the market boundary. Though the specific empirical application zeroes-in on environmental externality, the tools developed in this paper apply to a range of nonmarket entities.

The analytical modeling derives three discount rates: the market rate, an "environmental" rate, and an augmented rate. The analytical model yields the following expressions for the three discount rates discussed above. The market rate is simply the rate of return on private capital. The "environmental" rate is the rate of return on capital less the foregone returns due to the diversion of investment from capital to abatement. The augmented discount rate is the rate of return on private capital minus the partial effect of income on damages and abatement. By extension, the augmented rate departs from the market rate through two factors: the drag due to abatement expenditure, and the partial effect of income on damages. 
To explore the difference between the augmented and market rates more deeply, we begin by assuming, plausibly, that additional output weakly yields more abatement. In that case, in an economy with damages that rise with income, the augmented discount rate is less than the market rate. Because rising damages place a drag on augmented growth (Muller, 2014a; 2014b), the effect of damages reinforces the drag from abatement.

Contrarily, in a growing economy with falling damage, the effect of damages counteracts the drag due to abatement. Since growth is enhanced by the attenuation of damage the augmented discount rate will exceed the market rate if damage is relatively elastic in abatement; that is, if each unit expended on abatement yields more than one unit in damage reduction. In the case where damage is inelastic with respect to expenditure on abatement, the augmented rate will fall short of the market rate.

Figure III shows a plot of environmental damage relative to a conventional measure of income, GDP. The graph is divided into three regions that correspond to stages of development in which environmental damage is: increasing with income (I.), decreasing with greater income (II.), and fixed, perhaps reflecting binding policy constraints, in region III.. In regions I. and II., the graph assumes an inverted U-shape, which is just one of many possible forms to this relationship. This suggests the environmental Kuznets curve. In region I., an augmented discount rate is unambiguously lower than the market rate. The partial effect of income on both damages and abatement expenditure work in the same direction, dragging down the return to savings and, hence, the discount rate. Conversely, in region II. the partial effect of income on damages is negative. Expression (6) shows that this has the effect of increasing the augmented discount rate relative to the market rate. In region III., this hypothetical economy finds itself in the setting Weitzman (1994) modeled. Damages are fixed due, perhaps, to binding environmental policy constraints. In region III. the augmented rate falls below the market rate and is equal to Weitzman's (1994) environmental rate. 
The value in figure III is the ability to see how the magnitude of the augmented discount rate would change relative to the market rate as GDP (and the link between GDP and damage) changes. Lower augmented discount rates occur at levels of development characterized by rising damages and income. Higher rates occur in economies with damages that fall as income rises. In the context of climate policy (or any long run policy characterized by benefits that lag costs), the use of an augmented rate suggests more stringent policy in region I. and less stringent policy in region II. Then in region III. augmented discount rates would fall again as $\left(\frac{\partial D_{t}}{\partial Y_{t}}\right)$ approaches zero. For the relationship between income and GDP shown in figure III, this suggests a nonmonotonic term structure in discount rates. This stands in stark contrast to the recent literature that argues for a declining term structure (Arrow et al., 2014). Of course, many forms to the relationship shown in figure III are possible. This form may vary by country or pollutant. Therefore, whether or not the term structure of discount rates suggested by the results in this study would change (instead of just modifying) the recommended use of a declining discount rate is a matter left to future empirical work.

The analytical modeling also reports that if the marginal opportunity cost from investments in environmental quality just offset the marginal damage from additional output, then the augmented discount rate and the market rate will coincide. Hence, efficient management of environmental externality eliminates the difference in these discount rates.

The empirical analysis reports that Gross External Damages (GED) from air pollution and GHGs amounted to $\$ 770$ billion in 1999 and that this fell to $\$ 423$ billion in 2011. GED fell from 8.4 percent of output in 1999 to 3.6 percent in 2011. This finding indicates that the U.S. economy exhibited an inverse relationship between income and pollution damage over this 12 year period.

Employing reported GDP and the estimated GED, the difference between augmented and market growth rates ranged from 0.6 percent (1999 to 2002) to 0.3 percent (2002 to 
2011). Armed with the expression of the spread between augmented and market discount rates based on the Ramsey formula, along with a value of two for the elasticity of the marginal utility of income, the difference amounted to 1.24 percent from 1999 to 2002. The divergence then fell to under 1 percent for the remaining years under study.

As is well-known, the magnitude of the discount rate plays a central role in environmental policy design for stock pollutants like GHGs. More broadly, any benefitcost analysis that spans a long time horizon is quite sensitive to the discount rate because of the familiar mathematics of discounting. So, at least in principle, the analytical and empirical results presented in this paper have far-reaching consequences both for policy design and evaluation.

The framework developed herein is more general than merely applying to pollution damage, natural capital investment, or environmental accounting. In fact, this machinery is applicable to any context in which standard market measures of income are augmented to include non-market entities. Consider investment in national security; a society invests in physical capital and employs labor to reduce the risk of a terrorist attack or an invasion by another country. Such diversions of investment (from conventionally productive private capital investments to risk reduction measures) reduce the rate of return on savings when viewed through a market-centric measure of income. That is, if the return to such investments lies outside the scope of income, then the only dimension of this choice that manifests in the accounts is on the expenditure side - the opportunity cost of not investing in ordinary productive capital. By construction, the allocation of resources to national security places a drag on the yield of savings. In order to comprehensively capture the return to such expenditures, the definition of national income must include non-market measures of safety or risk. This paper shows generally how such investments affect comprehensive output and, in turn, discount rates. As such, the paper is of potentially broad interest and applicability. 
This paper suggests research on a number of fronts. In no particular order, a logical empirical extension of this analysis is to apply the framework to different countries. That is, while the U.S. economy exhibits damages inversely related to output, other contexts such as rapidly growing developing countries likely feature damages that have increased with output. What would this imply for estimates of growth and discount rates? Another area where the ideas set forth in this paper might be applied is by using an IAM like DICE to characterize a dynamically efficient abatement policy with endogenous discount rates of the type proposed herein. Finally, the issue of uncertainty is not raised here. Of course, both market and augmented measures of output and therefore growth are not measured with certainty. This implies that the discount rates the depend on these aggregates are also estimated with some degree of imprecision. A thorough treatment of uncertainty would be a worthwhile extension. In any event, the proposed modification to more standard approaches to calibration of discount rates is likely to have pronounced effects on policy design for GHGs or other long-lived environmental challenges. 
Tables.

Table I. Empirical Model Calibration: GED Inclusive Of Damage From Greenhouse Gas And Local Air Pollution Emissions.

\begin{tabular}{|c|c|c|c|c|}
\hline & (1) & (2) & (3) & (4) \\
\hline Year & $\begin{array}{l}Y_{t}=(G D P) \\
\text { (Billions, real \$) }\end{array}$ & $\begin{array}{l}\mathrm{D}_{\mathrm{t}}=(\mathrm{GED})^{\mathrm{A}} \\
(\text { Billions, real \$) }\end{array}$ & $\begin{array}{l}E_{t}=\left(Y_{t}-D_{t}\right) \\
\text { (Billions, real \$) }\end{array}$ & $\alpha_{t}=\frac{G E D_{t}}{G D P_{t}}$ \\
\hline 1999 & 9,164 & 768 & 8,395 & 0.084 \\
\hline 2002 & 9,877 & 661 & 9,216 & 0.067 \\
\hline 2005 & 10,718 & 632 & 10,086 & 0.059 \\
\hline 2008 & 11,101 & 535 & 10,566 & 0.048 \\
\hline 2011 & 11,816 & 423 & 11,393 & 0.036 \\
\hline
\end{tabular}


Table II. Empirical Estimates Of Growth Rates.

\begin{tabular}{|c|c|c|c|c|}
\hline \multicolumn{5}{|c|}{ Absolute Growth } \\
\hline & (1) & (2) & (3) & (4) \\
\hline Year & $\begin{array}{l}\text { GDP } \\
(\%)\end{array}$ & $\begin{array}{l}\text { GED } \\
(\%)\end{array}$ & $\begin{array}{l}\text { EVA } \\
(\%)\end{array}$ & $\begin{array}{l}\Delta=E V A-G D P \\
(\%)\end{array}$ \\
\hline 1999 & $*$ & $*$ & $*$ & $*$ \\
\hline 2002 & 2.529 & -4.878 & 3.159 & 0.630 \\
\hline 2005 & 2.761 & -1.484 & 3.053 & 0.291 \\
\hline 2008 & 1.177 & -5.403 & 1.562 & 0.385 \\
\hline 2011 & 2.102 & -7.531 & 2.544 & 0.441 \\
\hline \multicolumn{5}{|c|}{ Per-Capita Growth } \\
\hline & (1) & (2) & (3) & (4) \\
\hline Year & $\begin{array}{l}\text { GDP } \\
(\%)\end{array}$ & $\begin{array}{l}\text { GED } \\
(\%)\end{array}$ & $\begin{array}{l}\text { EVA } \\
(\%)\end{array}$ & $\begin{array}{l}\Delta=E V A-G D P \\
(\%)\end{array}$ \\
\hline 1999 & $*$ & $*$ & * & * \\
\hline 2002 & 0.711 & -6.565 & 1.330 & 0.619 \\
\hline 2005 & 1.845 & -2.363 & 2.134 & 0.289 \\
\hline 2008 & 0.226 & -6.292 & 0.607 & 0.381 \\
\hline 2011 & 1.273 & -8.282 & 1.711 & 0.438 \\
\hline
\end{tabular}


Table III. Empirical Estimates of Discount Rates Derived with Ramsey.

\begin{tabular}{cccc|cc}
\hline Year & $\begin{array}{c}r_{s}^{R} \\
(\%)\end{array}$ & $\begin{array}{c}\boldsymbol{\eta}=\mathbf{2} \\
r_{m}^{R} \\
(\%)\end{array}$ & $\begin{array}{c}\Delta=r_{s}^{R}-r_{m}^{R} \\
(\%)\end{array}$ & $\begin{array}{c}\boldsymbol{\eta}=\mathbf{1} \\
r_{s}^{R}-r_{m}^{R} \\
(\%)\end{array}$ & $\begin{array}{c}\eta=4 \\
=r_{s}^{R}-r_{m}^{R} \\
(\%)\end{array}$ \\
\hline 1999 & $*$ & $*$ & $*$ & $*$ & $*$ \\
2002 & $4.660^{\mathrm{A}}$ & 3.422 & 1.238 & 0.619 & 2.475 \\
2005 & 6.268 & 5.690 & 0.577 & 0.289 & 1.155 \\
2008 & 3.213 & 2.451 & 0.762 & 0.381 & 1.524 \\
2011 & 5.421 & 4.546 & 0.875 & 0.438 & 1.751 \\
\hline
\end{tabular}

A Estimates in table III assume pure rate of time preference of $0.02 . r_{e}^{R}=$ discount rate derived using augmented income. $r_{m}^{R}=$ discount rate derived using market income. Rates of growth are in per capita terms. 
Table IV. Comparison Of GED, EVA, And Pollution Intensity

With And Without GHGs.

\begin{tabular}{|c|c|c|c|c|c|c|}
\hline \multicolumn{4}{|c|}{ Local Pollution and GHGs } & \multicolumn{3}{|c|}{ Local Pollution } \\
\hline & (1) & (2) & (3) & (4) & (5) & (6) \\
\hline Year & $\begin{array}{l}\text { GED } \\
\text { (Billions, } \\
\text { real \$) }\end{array}$ & $\begin{array}{l}\text { EVA } \\
\text { (Billions, } \\
\text { real \$) }\end{array}$ & $\alpha_{t}=\frac{G E D_{t}}{G D P_{t}}$ & $\begin{array}{l}\text { GED } \\
\text { (Billions, } \\
\text { real \$) }\end{array}$ & $\begin{array}{l}\text { EVA } \\
\text { (Billions, } \\
\text { real \$) }\end{array}$ & $\alpha_{t}=\frac{G E D_{t}}{G D P_{t}}$ \\
\hline 1999 & $768^{\mathrm{A}}$ & 8,395 & 0.084 & 589 & 8,575 & 0.064 \\
\hline 2002 & 661 & 9,216 & 0.067 & 478 & 9,399 & 0.048 \\
\hline 2005 & 632 & 10,086 & 0.059 & 442 & 10,276 & 0.041 \\
\hline 2008 & 535 & 10,566 & 0.048 & 351 & 10,750 & 0.032 \\
\hline 2011 & 423 & 11,393 & 0.036 & 268 & 11,548 & 0.023 \\
\hline
\end{tabular}


Table V: Empirical Estimates Of Discount Rate Spreads Derived With Ramsey: The Contribution Of Local Air Pollutants And GHGs To GED.

\begin{tabular}{|c|c|c|c|c|c|c|}
\hline \multicolumn{4}{|c|}{ Local Pollution and GHGs } & \multicolumn{3}{|c|}{ Local Pollution } \\
\hline Year & $\begin{array}{l}\eta=2 \\
(\%)\end{array}$ & $\begin{array}{l}\eta=1 \\
(\%)\end{array}$ & $\begin{array}{l}\eta=4 \\
(\%)\end{array}$ & $\begin{array}{l}\eta=2 \\
(\%)\end{array}$ & $\begin{array}{l}\eta=1 \\
(\%)\end{array}$ & $\begin{array}{l}\eta=4 \\
(\%)\end{array}$ \\
\hline 1999 & * & * & $*$ & $*$ & $*$ & $*$ \\
\hline 2002 & 1.24 & 0.62 & 2.48 & 1.13 & 0.57 & 2.27 \\
\hline 2005 & 0.58 & 0.29 & 1.16 & 0.50 & 0.25 & 1.01 \\
\hline 2008 & 0.76 & 0.38 & 1.52 & 0.66 & 0.33 & 1.33 \\
\hline 2011 & 0.88 & 0.44 & 1.75 & 0.62 & 0.31 & 1.23 \\
\hline
\end{tabular}


Figure I:

Present Value Of Hypothetical \$100 million At $t$ Years In The Future.

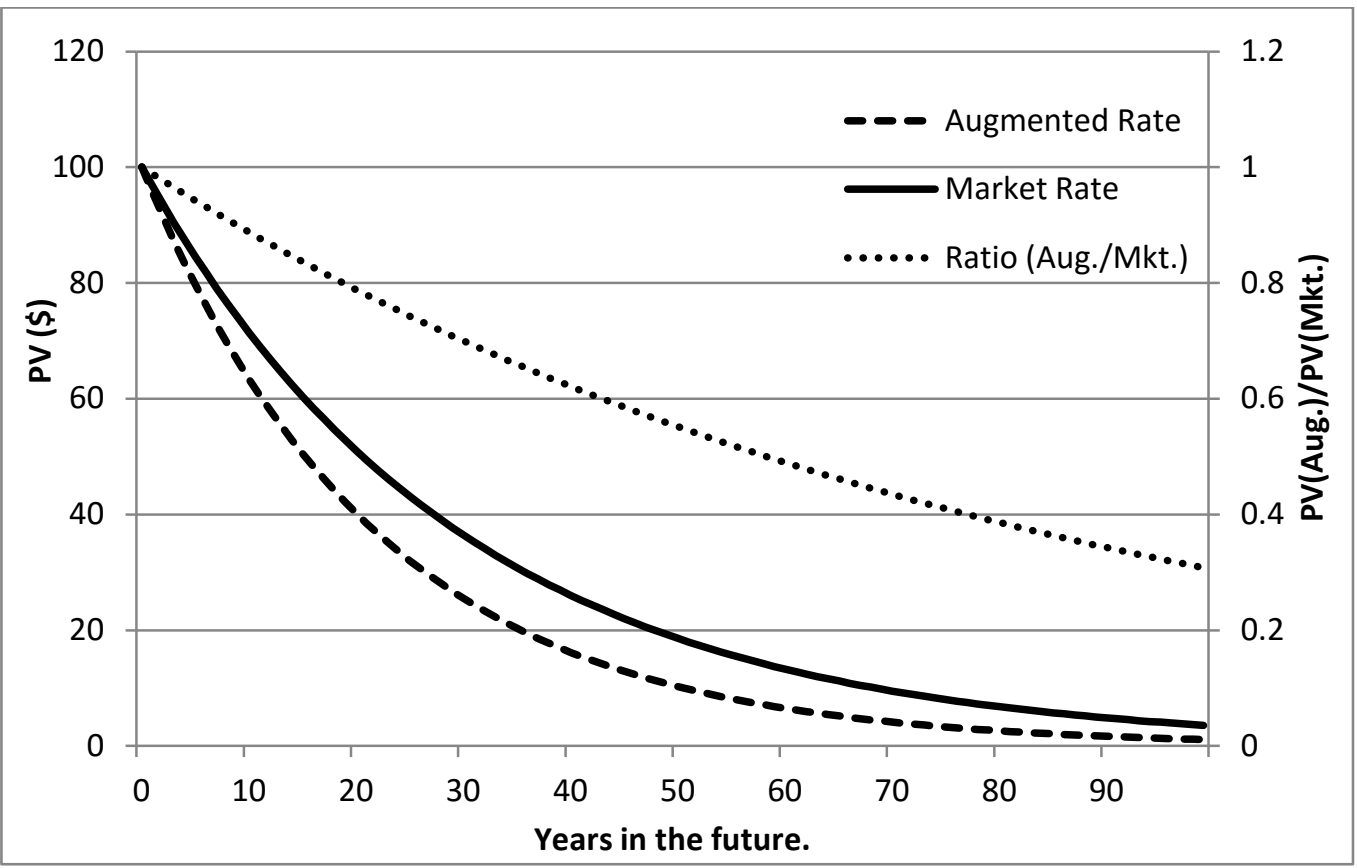

All estimates in figure I assume pure rate of time preference of 0.02 , eta $=2$. 


\section{Figure II:}

Present Value Sensitivity To Eta.

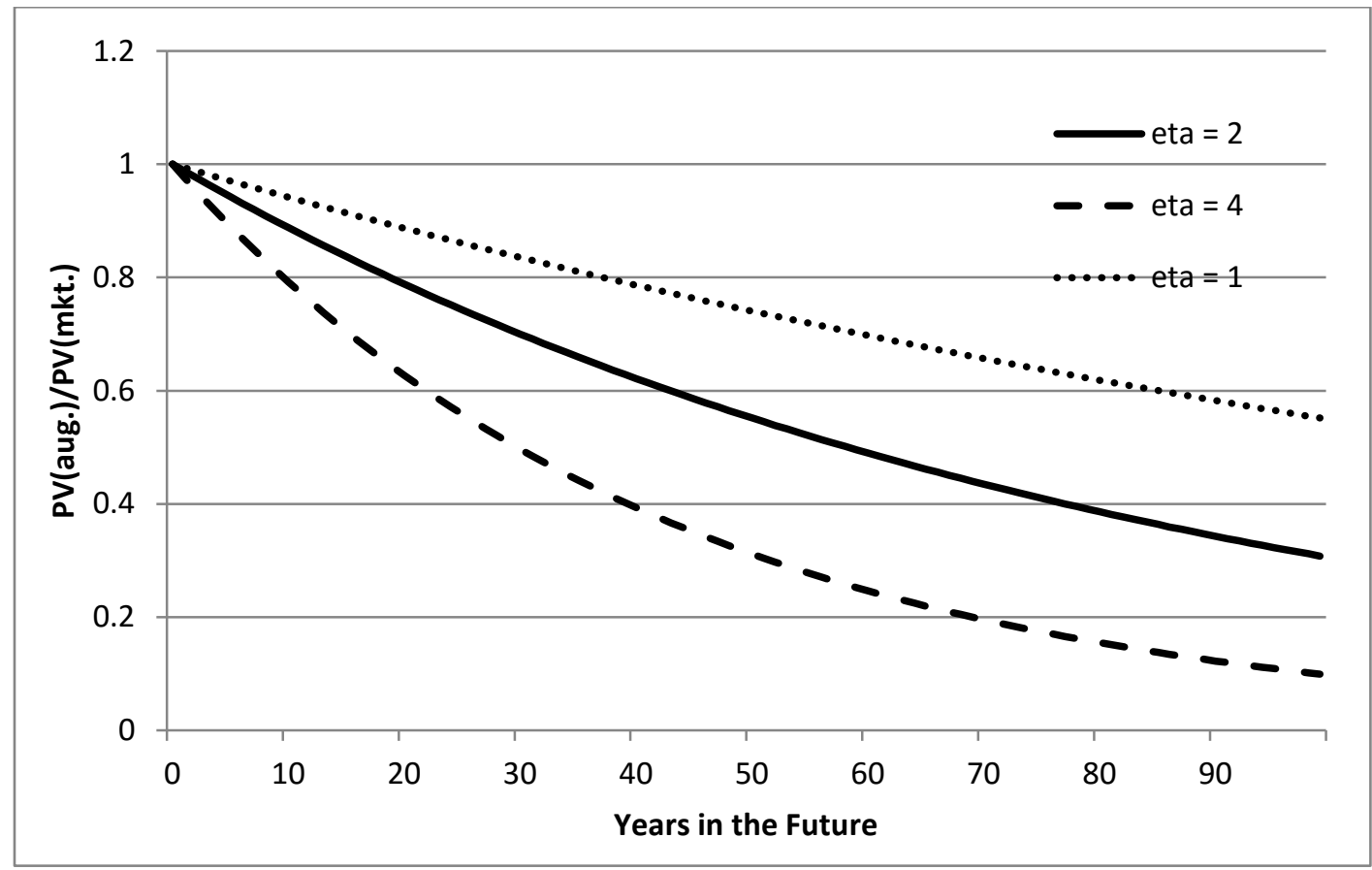

All estimates in figure II assume pure rate of time preference of 0.02 , eta variable as shown in figure. 
Figure III:

Schematic Of Relationship Between Environmental Pollution Damage And National Income.

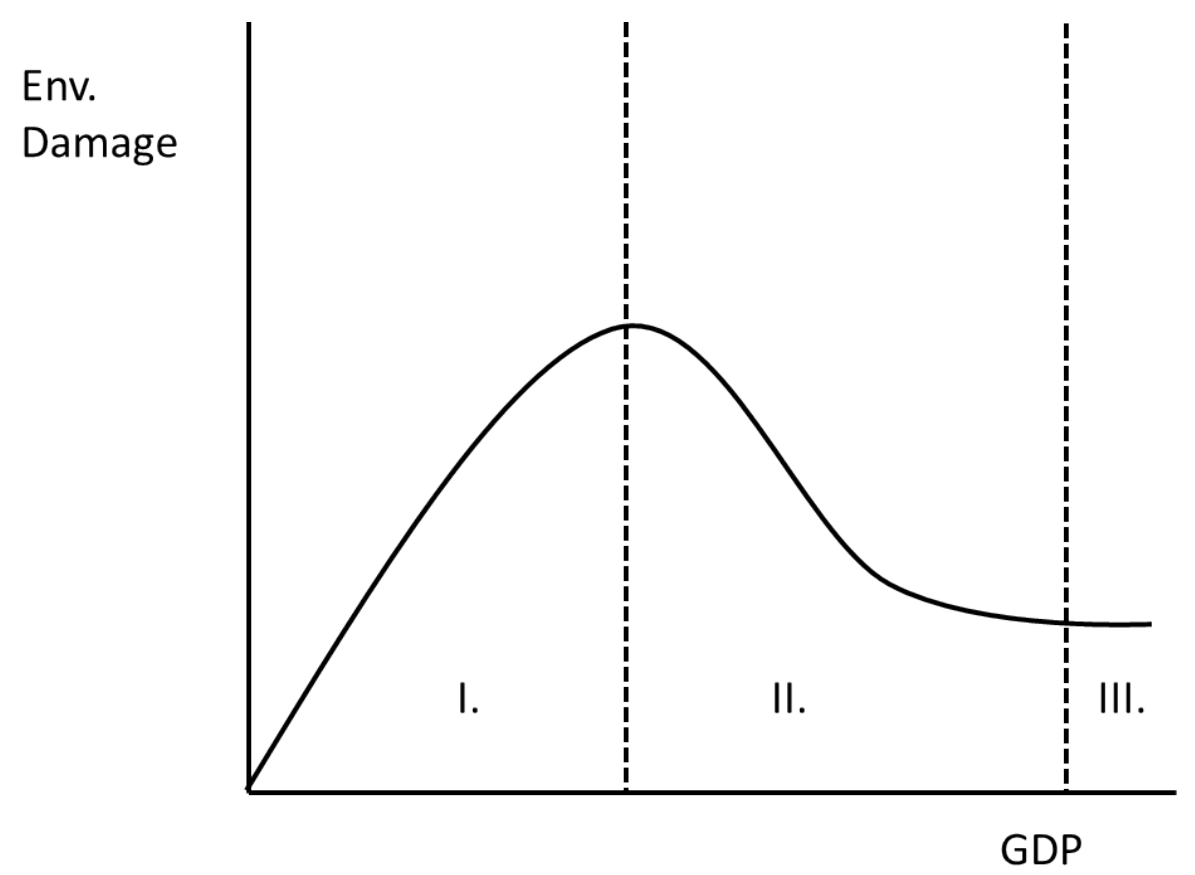




\section{References.}

1) Arrow, Kenneth J., William R. Cline, Karl-Goran Maler, M. Munasinghe, R. Squitieri, Joseph E. Stiglitz. 1995. Intertemporal equity, discounting, and economic efficiency. In Global Climate Change: Economic and Policy Issues, M. Munasinghe (ed.), World Bank Environment Paper 12, Washington, D.C. 1995, pp. 1-32. Reprinted in an abbreviated format as "Intertemporal Equity, Discounting, and Economic Efficiency," Climate Change 1995: Economic and Augmented Dimensions of Climate Change, J. Bruce, H. Lee, and E. Haites (eds.), Cambridge: Cambridge University Press, 1996, pp. 125-144.

2) Arrow, Kenneth J., Maureen Cropper, Christian Gollier, Ben Groom, Geoffrey Heal, Richard G. Newell, William D. Nordhaus, Robert S. Pindyck, William A. Pizer, Paul R. Portney, Thomas Sterner, Richard S.J. Tol, and Martin L. Weitzman. 2014. "Should Governments Use a Declining Discount Rate in Project Analysis?" Review of Environmental Economics and Policy, 8(2), 145-163.

3) Bartelmus, Peter. 2009. "The cost of natural capital consumption: Accounting for a sustainable world economy." Ecological Economics. 68: 1850 - 1857.

4) Baumol, William J. 1968. "On the Social Rate of Discount." American Economic Review. 58(4): 788-802.

5) Bell, Michelle L., A. McDermott, Scott L. Zeger, Jonathan M. Samet, and Francesca Domenici. 2004. “Ozone and Short-Term Mortality in 95 US Urban Communities, 1987-2000." J. of the Amer. Medical Association, 17: 2372-2378.

6) Bradford, David. 1975. “Constraints on Government Investment Opportunities and the Choice of Discount Rates." American Economic Review. 65: 887-899.

7) Centers for Disease Control and Prevention (CDC), Accessed 2015. http://wonder.cdc.gov/cmf-icd10.html).

8) Cropper, Maureen L., Mark C. Freeman, Ben Groom, William A. Pizer. 2014. Declining Discount Rates. American Economic Review: Papers and Proceedings. 104(5) 538-543. 
9) Das, Mausumi. 2003. "Optimal growth with decreasing marginal impatience." Journal of Economic Dynamics and Control. 27: 1881-1898.

10) Epstein, Larry G., J. Allan Hynes. 1983. "The Rate of Time Preference and Dynamic Economic Analysis." Journal of Political Economy. 91(4): 611 - 635.

11) Gollier, Christian. 2008. Discounting with fat-tailed economic growth. Journal of Risk and Uncertainty. 37(2-3): 171 - 86.

12) Gollier, Christian. 2011. Pricing the future: The economics of discounting and sustainable development. Princeton University Press. Princeton, N.J., USA.

13) Heal, Geoffrey. 2009. “The economics of climate change: a post-stern perspective.” Climatic Change. 96: 275-297.

14) Heal, Geoffrey. 2012. "Reflections - Defining and Measuring Sustainability." Review of Environmental Economics and Policy. 6(1): 147-163.

15) Holland, Stephen P., Erin T. Mansur, Nicholas Z. Muller, Andrew J. Yates. 2015. Environmental Benefits from Driving Electric Vehicles? National Bureau of Economic Research Working Paper: w21291.

16) Jaramillo, Paulina, Nicholas Z. Muller. 2016. “The Air Pollution Damage from Energy production in the U.S: 2002 - 2008." Energy Policy. 90: 202 - 211.

17) Le Kama, Alain Ayong, Katheline Schubert. 2007. “A Note on the Consequences of an Endogenous Discounting Depending on the Environmental Quality." Macroeconomic Dynamics. 11: 272-289.

18) Levy, Jonathan I., Lisa K. Baxter, Joel Schwartz. 2009. "Uncertainty and Variability in Health-Related Damages from Coal-fired Power Plants in the United States." Risk Analysis.

19) Maler, Karl-Goran, 1991. "National Accounts and Environmental Resources." Environmental and Resource Economics. 1: 1 - 15.

20) Maler, Karl-Goran, S. Aniyar, A. Jansson. 2008. “Accounting for ecosystem services as a way to understand the requirements for sustainable development." Proceedings of the National Academy of Science. 105(28): 9501-9506. 
21) Marglin, Stephen A. 1963a. “The Social Rate of Discount and the Optimal Rate of Investment." Quarterly Journal of Economics. 77(1): 95-111.

22) Marglin, Stephen A. 1963b. "The Opportunity Cost of Public Investment." Quarterly Journal of Economics. 77(2): 274-289.

23) Michalek, Jeremy J., Mikhail Chester, Paulina Jaramillo, Constantine Samaras, Ching-Shin Norman Shiau, Lester B. Lave. 2011. Valuation of plug-in vehicle lifecycle air emissions and oil displacement benefits. Proceedings of the National Academy of Science. www.pnas.org/cgi/doi/10.1073/pnas.1104473108

24) Mendelsohn, Robert O., 1981. “The Choice of Discount Rate for Public Projects." American Economic Review. 71(1): 239 - 241.

25) Muller Nicholas Z., Robert O. Mendelsohn, 2007. Measuring the Damages Due to Air Pollution in the United States. Journal of Environmental Economics and Management. 54: 1 - 14.

26) Muller Nicholas Z., Robert O. Mendelsohn, 2009. Efficient Pollution Regulation: Getting the Prices Right. American Economic Review. 99(5): 1714 - 1739.

27) Muller, Nicholas Z., Robert O. Mendelsohn, and William D. Nordhaus, 2011. Environmental Accounting for Pollution in the U.S. Economy. American Economic Review. 101(5): 1649 - 1675.

28) Muller, Nicholas Z. 2011. Linking Policy to Statistical Uncertainty in Air Pollution Damages. The B.E. Press Journal of Economic Analysis and Policy. Vol. 11(1), Contributions, Article 32.

29) Muller, Nicholas Z. 2013 "Using Index Numbers for Deflation in Environmental Accounting." Environment and Development Economics. doi:10.1017/S1355770X1300048X.

30) Muller, Nicholas Z. 2014a. “Towards the Measurement of Net Economic Welfare: Air Pollution Damage in the United States National Accounts - 2002, 2005, 2008." In: Measuring Economic Sustainability and Progress. Eds. Jorgensen, D.W., J.S. Landefeld, P. Schreyer. NBER Book Series in Income and Wealth Vol. 72. 31) Muller, Nicholas Z. 2014b. "Boosting GDP growth by accounting for the environment: Including air pollution and greenhouse gas damages increases 
estimated U.S. growth." Science. August 22nd, 2014, Vol. 345 no. 6199 pp. 873-874: DOI:10.1126/science.1253506.

32) NAS NRC. 2010. Hidden Costs of Energy: Unpriced Consequences of Energy Production and Use; National Academy Press, Washington, D.C., USA.

33) Nordhaus, William D. 2006. "Principles of National Accounting for Non-Market Accounts." In D.W. Jorgensen, J.S. Landefled, and W.D. Nordhaus, eds. A New Architecture for the U.S. National Accounts. NBER Studies in Income and Wealth. Vol. 66, The University of Chicago Press. Chicago, Il, USA.

34) Nordhaus, William, D. 2007. "Critical Assumptions in the Stern Review on Climate Change," Science, Vol. 317. no. 5835, pp. 201-202

35) Polasky, Stephen, Benjamin Bryant, Peter Hawthorne, Justin Johnson, Bonnie Keeler, Derric Pennington. 2015. "Inclusive Wealth as a Metric of Sustainable Development." Annual Review of Environment and Resources. 40:445-66.

36) Pope, C. Arden, Richard T. Burnett, Michael J. Thun, Eugenia E. Calle, Daniel Krewski, Kazuhiko Ito, George D. Thurston. 2002. “Lung Cancer, Cardiopulmonary Mortality, and Long-Term Exposure to Fine Particulate Air Pollution." J. of the Amer. Medical Association, 287 (9): 1132-1141.

37) Ramsey, Frank P. 1928. A Mathematical Theory of Saving. Economic Journal 38 (152): 543-559.

38) Six, Magdalena , Franz Wirl. 2015. “Optimal pollution management when discount rates are endogenous." Resource and Energy Economics. 42: 53 - 70.

39) Solow, Robert. 1956. A Contribution to the Theory of Economic Growth. Quarterly Journal of Economics 70 (1): 65-94.

40) Steiner, Peter O. 1959. “Choosing Among Alternative Public Investments in the Water Resource Field." American Economic Review. 49(5): 893-916.

41) Stern, Nicholas. 2007. The Economics of Climate Change: The Stern Review. Cambridge, UK: Cambridge University Press, online at 
http://www.hmtreasury.gov.uk/independent_reviews/stern_review_economic s_climate_change/st ernreview_index.cfm.

42) Tol, Richard S. J. (2008). The Augmented Cost of Carbon: Trends, Outliers and Catastrophes. Economics: The Open-Access, Open-Assessment E-Journal, 2 (200825). http://dx.doi.org/10.5018/economics-ejournal.ja.2008-25

43) United States Bureau of the Census, (Census), 2015. http://www.census.gov/popest/

44) United States Bureau of Economic Analysis, (USBEA), 2007. An Introduction to the National Income and Product Accounts. Methodology Papers: U.S. National Income and Product Accounts.

45) United States Bureau of Economic Analysis, (USBEA), 2014. Interactive Tables. http://www.bea.gov/iTable/iTable.cfm?ReqID=9\&step=1\#reqid=9\&step=1\&is $\underline{\text { uri }=1}$

46) United States Department of Agriculture (USDA), 2015. http://www.agcensus.usda.gov/

47) United States Environmental Protection Agency. 2002. National Emissions Inventory (NEI), 2002. Washington, DC: Office of Air Quality Planning and Standards, Emissions Inventory Group; Emissions, Monitoring, and Analysis Division.

48) United States Environmental Protection Agency. 2005. National Emissions Inventory (NEI), 2002. Washington, DC: Office of Air Quality Planning and Standards, Emissions Inventory Group; Emissions, Monitoring, and Analysis Division.

49) United States Environmental Protection Agency. 2008. National Emissions Inventory (NEI), 2005. Washington, DC: Office of Air Quality Planning and Standards, Emissions Inventory Group; Emissions, Monitoring, and Analysis Division. 
50) United States Environmental Protection Agency. 2011. National Emissions Inventory (NEI), 2008. Washington, DC: Office of Air Quality Planning and Standards, Emissions Inventory Group; Emissions, Monitoring, and Analysis Division.

51) United States Environmental Protection Agency. 2014. National Emissions Inventory (NEI), 2011. Washington, DC: Office of Air Quality Planning and Standards, Emissions Inventory Group; Emissions, Monitoring, and Analysis Division.

52) Viscusi, W. Kip, Joseph E. Aldy. The Value of a Statistical Life: A Critical Review of Market Estimates Throughout the World, J. of Risk and Uncertainty. 27 (1) (2003) $5-76$.

53) Weitzman, Martin L. 1994. On the Environmental Discount Rate. Journal of Environmental Economics and Management. 26: 200 - 209.

54) Weitzman, Martin L. 2001. Gamma Discounting. American Economic Review. 91(1): 260-271. 


\section{Mathematical Appendix.}

This appendix shows the calculation of discount rates in a more explicit fashion than the space constraints in the text permit.

\section{a. Accounting Framework.}

A homogeneous output $\left(Y_{t}\right)$ is expressed in terms of the standard accounting identity shown in (A1).

$Y_{t}=C_{t}+I_{t}+G_{t}+X_{t}$

where: $C_{t}=$ consumption of market goods.

$I_{t}=K_{t}-\lambda K_{t-1}$ : net investment in physical capital, where $\lambda$ is the depreciation of physical capital.

$G_{t}=$ government expenditure.

$X_{t}=$ net exports.

The standard framework is augmented in two ways. Let $A_{t}$ represent expenditure on abatement of pollution. This is defined as a linear function of income: $A_{t}=\gamma Y_{t}$. This extension is shown in (A2).

$Y_{t}-\gamma Y_{t}=C_{t}+I_{t}+G_{t}+X_{t}$

The second extension of (A1) features the inclusion of environmental damage (denoted $\left.D_{t}\right)$ in the expression for income. Damage is modeled as a linear function of income and abatement: $D_{t}=\alpha Y_{t}-\beta\left(\gamma Y_{t}\right)$. The $(\alpha)$ parameter represents the pollution-intensity of output, while the $(\beta)$ parameter reflects the sensitivity of environmental damage to investment in abatement. Mechanically, damage increases proportionally to output through $(\alpha)$, and decreases with income through investment in abatement $(\gamma)$. With $\left(D_{t}\right)$ characterizing environmental damage in time $(t)$, environmentally-adjusted output is shown in (A3).

$Y_{t}(1-\gamma-\alpha+\beta \gamma)=C_{t}+I_{t}+G_{t}+X_{t}$ 


\section{b. Derivation of discount rates.}

This section derives the discount rates using the three accounting frameworks presented above. Conditional on an investment shock, the approach solves for the change in consumption that balances the accounting identity. Dividing the change in consumption by the savings shock $\left(\varepsilon_{\mathrm{t}}\right)$ yields an expression for the rate of return on savings. Using the market accounts to demonstrate, first, solve for consumption as shown in (A4) and (A5).

$$
\begin{aligned}
& Y_{t}-\left(I_{t}+G_{t}+X_{t}\right)=C_{t}^{0} \\
& \left(Y_{t}+\delta^{c} \varepsilon_{t}\right)-\left(I_{t}+\varepsilon_{t}+G_{t}+X_{t}\right)=C_{t}^{s}
\end{aligned}
$$

Then take the difference (A5) - (A4) and divide through by $\left(\varepsilon_{t}\right)$.

$\frac{C_{t}^{S}-C_{t}^{0}}{\varepsilon_{t}}=\frac{\delta^{c} \varepsilon_{t}-\varepsilon_{t}}{\varepsilon_{t}}=\delta^{c}-1=r$

Repeating this procedure with abatement:

$$
\begin{aligned}
& \left(Y_{t}-\gamma Y_{t}\right)-\left(I_{t}+G_{t}+X_{t}\right)=C_{t}^{0} \\
& \left(Y_{t}+\delta^{c} \varepsilon_{t}\right)(1-\gamma)-\left(I_{t}+\varepsilon_{t}+G_{t}+X_{t}\right)=C_{t}^{S} \\
& \frac{C_{t}^{S}-C_{t}^{0}}{\varepsilon_{t}}=\frac{\delta^{c} \varepsilon_{t}-\delta^{c} \gamma \varepsilon_{t}-\varepsilon_{t}}{\varepsilon_{t}}=\delta^{c}-\delta^{c} \gamma-1=r-(1+r)\left(\frac{\partial A_{t}}{\partial Y_{t}}\right) .
\end{aligned}
$$

Repeating this procedure with abatement and environmental damage:

$$
\begin{aligned}
& Y_{t}(1-\gamma-\alpha+\beta \gamma)-\left(I_{t}+G_{t}+X_{t}\right)=C_{t}^{0} \\
& \left(Y_{t}+\delta^{c} \varepsilon_{t}\right)(1-\gamma-\alpha+\beta \gamma)-\left(I_{t}+\varepsilon_{t}+G_{t}+X_{t}\right)=C_{t}^{S} \\
& \frac{C_{t}^{s}-C_{t}^{0}}{\varepsilon_{t}}=\frac{\delta^{c} \varepsilon_{t}-\delta^{c} \gamma \varepsilon_{t}-\delta^{c} \varepsilon_{t}(\alpha-\beta \gamma)+\varepsilon_{t}}{\varepsilon_{t}}=\delta^{c}-\delta^{c} \gamma-\delta^{c}(\alpha+\beta \gamma)-1=r-(r+1)\left(\frac{\partial D_{t}}{\partial Y_{t}}+\frac{\partial A_{t}}{\partial Y_{t}}\right)
\end{aligned}
$$




\section{c. Comparing the different discount rates.}

With the expressions for the market, environmental, and augmented discount rates the analysis next compares these rates.

$i^{m}=r$

$i^{e}=r-(1+r)\left(\frac{\partial A_{t}}{\partial Y_{t}}\right)$

$i^{e}-i^{m}=-(r+1)\left(\frac{\partial A_{t}}{\partial Y_{t}}\right)$

The $(r+1)\left(\frac{\partial A_{t}}{\partial Y_{t}}\right)$ term represents the reduction in the return on savings due to the diversion of some savings to pollution abatement. Thus, provided $(\gamma)>0$, and therefore $\left(\frac{\partial A_{t}}{\partial Y_{t}}\right)>0, i^{e}-i^{m}<0$. This confirms Weitzman's (1994) result in the present framework.

$i^{a}=r-(r+1)\left(\frac{\partial D_{t}}{\partial Y_{t}}+\frac{\partial A_{t}}{\partial Y_{t}}\right)$

$i^{a}-i^{e}=-(r+1)\left(\frac{\partial D_{t}}{\partial Y_{t}}\right)$

The difference between the environmental and augmented rates reduces to (negative one times) the rate of return on capital times the partial effect of output on damages. The penalty on the rate of return due to additional abatement, $(1+r) \gamma$, manifests in both (A14) and (A16). So $(1+r) \gamma$ falls out of the difference. However, the effect of abatement on damage, $\beta \gamma$, occurs only in (A16) because only the augmented accounting identity recognizes damage. The difference between (A16) and (A14) centers on this additional term and its magnitude relative to $(\alpha)$.

Recall that $\left(\frac{\partial D_{t}}{\partial Y_{t}}\right)=\alpha-\beta \gamma$. The sign of $\left(\frac{\partial D_{t}}{\partial Y_{t}}\right)$, therefore, depends on three parameters: the pollution intensity of output $(\alpha)$, the responsiveness of abatement to output $(\gamma)$, and 
the responsiveness of damage (environmental quality) to abatement ( $\beta$ ). If $\alpha>\beta \gamma$, then $\left(\frac{\partial D_{t}}{\partial Y_{t}}\right)>0$, damages are increasing with income, and the rate of return is less than the environmental rate. However, if the environmental improvement from abatement, or $\beta \gamma$, is greater than pollution intensity then $\left(\frac{\partial D_{t}}{\partial Y_{t}}\right)<0$. In this case, damages decrease with output, and (A16) exceeds (A14).

The difference between Weitzman's environmental rate and augmented discount rates depends on the sign of $\left(\frac{\partial D_{t}}{\partial Y_{t}}\right)$. In an economy characterized by damages that decrease with income, the boost to output generated by saving in productive capital reduces damage, on net. That is, while some output is diverted to abatement and that produces a drag on returns, it also produces non-market benefits: the reduction in damage coming from the $\beta \gamma$ term. Under the $\alpha<\beta \gamma$ condition, accounting for changes to environmental damage resulting from diversion of savings to abatement increases the rate of return on savings relative to simply deducting diversions of abatement costs from savings. In economies where each additional unit of output generates more harm, $(\alpha>\beta \gamma)$, there is an additional drag on investment due to the additional damage. Thus, $(\mathrm{A} 16)<(\mathrm{A} 14)$.

The conclusions above should be intuitive to the reader. Weitzman's (1994) insight that rerouting some savings to abatement reduces the return on savings only recognizes the opportunity cost of the re-allocation: $\gamma(1+r)$. In contrast, (A3), (A12), and (A16) also include the change in damage from additional abatement. In the augmented accounts (A3), prior empirical work has shown that reduced damages boost output, all else equal (Muller, 2014a; 2014b). So, if damages fall with output, the return on savings must rise relative to the case in which damages are ignored ${ }^{13}$.

\footnotetext{
13 This analysis assumes that the parameters $(\alpha, \beta, \gamma)$ are fixed. Of course, each of these parameters may change. One mway to explore the influence of such changes is through the term structure of the various discount rates. A rudimentary analysis of the term structure is conducted in the appendix to this paper.
} 
To contrast sharply, or directly, to Weitzman's (1994) case in which damages are held fixed despite the increase in output from savings, begin by noting that $\left(\frac{\partial D_{t}}{\partial Y_{t}}\right)=0$, if $\gamma=\frac{\alpha}{\beta}$. When expression (A17) is evaluated at $\gamma=\frac{\alpha}{\beta}$, the difference between the augmented and environmental rates is zero. By holding damages fixed the $\left(\frac{\partial D_{t}}{\partial Y_{t}}\right)$ term and (A17) equals zero. Expression (A18) displays the difference between $i^{a}$ and $i^{m}$ which is shown in the main body of the paper.

$i^{a}-i^{m}=\delta^{c}(\beta \gamma-\alpha)=-(r+1)\left(\frac{\partial D_{t}}{\partial Y_{t}}+\frac{\partial A_{t}}{\partial Y_{t}}\right)$

\section{d. Term Structure.}

Term structure refers to the time path of discount rates. The conceptual modeling above and in the main body of the paper does not explicitly treat changes in the discount rates over time. In order to explore the term structure of discount rates, the analysis begins by taking the partial derivatives of $i^{a}$ and $i^{e}$ according to three model parameters: $(\beta, \gamma, \alpha)$. That is, for fixed parameters, the partial effect of inter-temporal changes in output $\left(\mathrm{Y}_{t}\right)$

on both $i^{a}$ and $i^{e}$ are: $\frac{\partial D_{t}}{\partial Y_{t}}=\alpha-\beta \gamma$, and $\frac{\partial A_{t}}{\partial Y_{t}}=\gamma$. However, it is likely that the three model parameters: $(\beta, \gamma, \alpha)$, may also change over time. The following section briefly explores how such changes will affect $i^{a}$ and $i^{e}$.

Beginning with expenditure on abatement $(\gamma)$ :

$\frac{\partial i^{e}}{\partial \gamma}=-\delta^{c}$

$\frac{\partial i^{a}}{\partial \gamma}=\delta^{c}(\beta-1)$

Expression (A19) indicates that the partial effect of expenditure on abatement on the environmental discount rate is negative, provided private capital is productive. Further, the more productive is private capital (the higher the return to investment in capital) the steeper is the gradient of $i^{e}$ with respect to additional investment in abatement. As 
shown in (A20), the term structure of $i^{a}$ depends on both $\delta^{c}$ and $\beta$, the responsiveness of environmental quality (or natural capital) to investment in abatement - or natural capital, more generally. Thus, if $\beta<1$, then the gradient of $i^{a}$ with respect to $(\gamma)$ is negative and is less steep than that of $i^{e}$. Importantly, the term structure of $i^{a}$ with respect to $\gamma$ is rising if each monetary unit of investment in natural capital yields more than one unit of damage reduction.

Expression (A21) indicates that the partial effect of pollution intensity $(\alpha)$ on the augmented discount rate is simply negative one times the marginal product of private capital.

$\frac{\partial i^{a}}{\partial \alpha}=-\delta^{c}$

Thus, if pollution intensity falls (rises), the term structure of $i^{a}$ will rise (fall).

$\frac{\partial i^{a}}{\partial \beta}=\delta^{c} \gamma$

Expression (A22) shows that the partial effect of the sensitivity of environmental quality to abatement $(\beta)$ on the augmented discount rate is the marginal product of private capital times the share of output invested in environmental quality. Thus, provided $\gamma>0 i^{a}$ rises with greater responsiveness of natural capital to investment in natural capital.

\section{e. Discount Rates in the Ramsey Model.}

The familiar Ramsey (1928) formulation is shown in (A23).

$r^{R}=\rho+\eta g$

The parameters in (A23) assume their conventional meanings with $\rho=$ the pure rate of time preference; $\eta=$ the elasticity of the marginal utility of income; $g=$ annual, per capita income growth. In the following $(g)$ is replaced with a more explicit representation of per capita income growth to facilitate a comparison between market 
and augmented income. Thus, (A24), relies on market income, where $\left(Y_{t}\right)$ denotes national income in time period $(t)$, while $\left(P_{t}\right)$ is population in period $(\mathfrak{t})$.

$r_{m}^{R}=\rho+\eta\left(\frac{\frac{Y_{t+1}}{P_{t+1}}-\frac{Y_{t}}{P_{t}}}{\frac{Y_{t}}{P_{t}}}\right)$

Expression (A25) employs the augmented measure of national output: $\left(Y_{t}-\alpha_{t} Y_{t}\right)$, where $\alpha_{t}$ represents pollution damage intensity of output. Therefore, $\alpha_{t} Y_{t}=D_{t}$.

$r_{s}^{R}=\rho+\eta\left(\frac{\left(\frac{Y_{t+1}}{P_{t+1}}-\alpha_{t+1} \frac{Y t+1}{P_{t+1}}\right)-\left(\frac{Y_{t}}{P_{t}}-\alpha_{t} \frac{Y_{t}}{P_{t}}\right)}{\left(\frac{Y_{t}}{P_{t}}-\alpha_{t} \frac{Y t}{P_{t}}\right)}\right)$

Then, taking the difference by subtracting (A24) from (A25) yields:

$$
\Delta=r_{s}^{R}-r_{m}^{R}=\eta \frac{P_{t}}{P_{t+1}} \frac{Y_{t+1}}{Y_{t}}\left(\frac{\left(\alpha_{t}-\alpha_{t+1}\right)}{1-\alpha_{t}}\right)
$$

\section{f. Growth in the National Accounting Framework.}

This section derives growth rates in the market accounts, the accounts with abatement, and the augmented accounting framework. Beginning with the market accounts growth due to productive investment is characterized by:

$\frac{\left(Y_{t}+(1+r) \varepsilon_{t}\right)-Y_{t}}{Y_{t}}$

With abatement expenditure, growth is shown in (A28).

$\frac{\left(Y_{t}+(1+r) \varepsilon_{t}-\gamma\left(Y_{t}+(1+r) \varepsilon_{t}\right)\right)-Y_{t}}{Y_{t}}$

Finally, growth in the complete augmented accounts is:

$\frac{\left(Y_{t}+(1+r) \varepsilon_{t}-\gamma\left(Y_{t}+(1+r) \varepsilon_{t}\right)-\left(\alpha\left(Y_{t}+(1+r) \varepsilon_{t}\right)-\beta \gamma\left(Y_{t}+(1+r) \varepsilon_{t}\right)\right)\right)-Y_{t}}{Y_{t}}$

Replacing $(\gamma)$ with $\left(\frac{\partial A_{t}}{\partial Y_{t}}\right)$, the difference between (A28) and (A27) amounts to: 
$-\frac{\left(\frac{\partial A_{t}}{\partial Y_{t}}\right)\left(Y_{t}+(1+r) \varepsilon_{t}\right)}{Y_{t}}$

Thus, provided private capital is productive, implying $\left(Y_{t}+(1+r) \varepsilon_{t}\right)>Y_{t}$, then (A30) $<0$, and abatement reduces growth relative to the case without abatement.

The difference between (A29) and (A27) is shown in (A31):

$$
-\frac{\left(\left(\frac{\partial A_{t}}{\partial Y_{t}}\right)+\left(\frac{\partial D_{t}}{\partial Y_{t}}\right)\right)\left(Y_{t}+(1+r) \varepsilon_{t}\right)}{Y_{t}}
$$

The difference between augmented growth and market growth depends on both how abatement and damages change with output. Assuming $\left(\frac{\partial A_{t}}{\partial Y_{t}}\right)>0$, rising damage ensures that augmented growth falls short of market growth. In contrast, when damages fall with output, growth in augmented output may exceed or be less than market growth. This depends on the relative magnitudes of damage reduction and abatement expenditure. 
Graphical Appendix.

Figure A1: GED, GDP, and Adjusted Output.

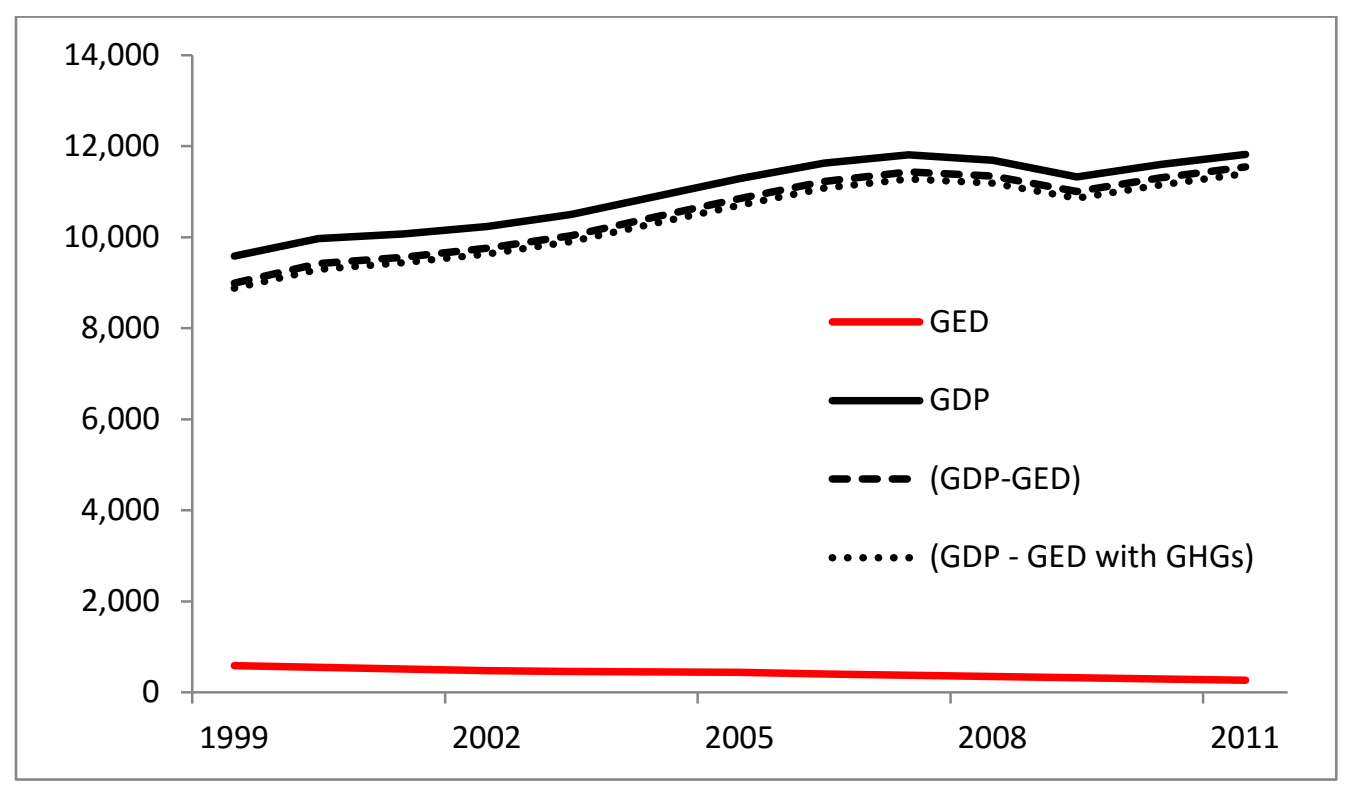

Vertical axis in (\$ billions, y2000 real).

GDP values for non-modeled years from USBEA.

GED values for non-modeled years linearly interpolated. 
Figure A3: Annual Environmental Pollution Damage Intensity.

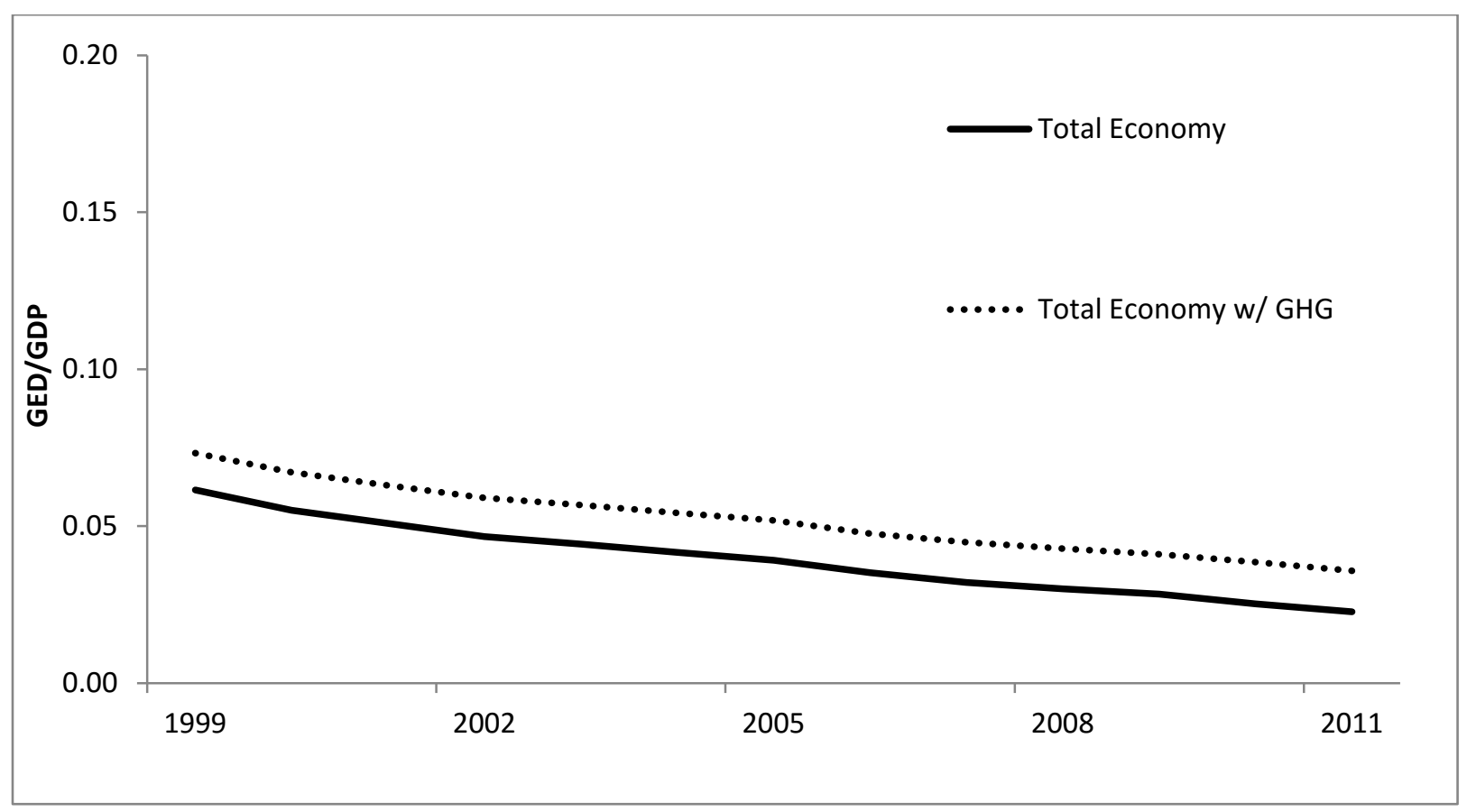

